\title{
Potential and Real Operating Leverage
}

\author{
Marco A. Paganini ${ }^{1}$ \\ ${ }^{1}$ Managing Director, Talento Risorse Umane S.r.l., Milan, Italy \\ Correspondence: Marco A. Paganini, Talento Risorse Umane S.r.l., Via Ippolito Rosellini, 8, 20124, Milan, Italy. \\ Tel: 39-02-4398-2400. E-mail: paganini@talentorisorseumane.it
}

Received: June 26, 2019

doi:10.5539/ijef.v11n8p138
Accepted: July 18, 2019

Online Published: July 30, 2019

URL: https://doi.org/10.5539/ijef.v11n8p138

\begin{abstract}
In this paper has been analysed the EBIT dynamic of a firm with high margins, strong revenues growth not paired by an adequate EBIT growth. The concept of the Degree of Operating Leverage developed by the economic literature was useful to highlight such a problem without explaining the root causes. Even standard income statement analyses cannot explain in depth such an unsatisfactory trend without turning to management accounting that was not available, like in many SMEs. The Author used some information coming from income statements, Revenues accounting and the discrimination between Variable and Fixed Costs to investigate the business case. He developed a method that throws light on EBIT dynamic between two financial periods in terms of quantity, mix, price and cost variations either managed or planned by the Top Management. The basic finding is that EBIT dynamic is explained by some parameters in period 1, the past period, and some variations in period 2 , the current period. The link between such periods is the Degree of Operating Leverage, declined in an ex-ante measure, already given for the past period, and the variations of the current period that determines its ex-post measure. In this framework becomes immediately glaring how it is possible to find high margins coupled with inadequate EBIT growth and where the faults lie. In general, the method developed is very useful to understand the EBIT dynamic of any firm and to plan its future course more accurately.
\end{abstract}

Keywords: dynamic, EBIT, ex-ante, fixed cost, mix, operating leverage, price, quantity, variable cost, variance, variation

\section{Introduction}

During the summer 2018, I developed the 2018-2022 business plan for a client of mine, active in a high-tech industry with an innovative offering that is considered as a market benchmark. Together with the Sales Director, I have been involved in the development of sales for several years and in other related activities such as the organizational development, working capital monitoring, in particular receivables, and the business intelligence system used to monitor Sales activities, Revenues and Budget Achievement.

Although I was never been officially involved in the analysis of corporate profitability, it has long been known that Revenues growth has not always been paired by an adequate growth of EBIT or Operating Result.

The elaboration of the 2018-2022 five-year plan offered me the opportunity to examine the cost structure in great details and to compute some financial ratios over a sufficiently long and representative period, from 2015 to 2022 with the 2015-2017 financial statements, 2018 budget and 2019-2022 business plan, providing a significant trend of the relevant facts that can be useful to analyse the company's profitability from an internal perspective, having access to all company information and in particular to the allocation between Variable Costs and Fixed Costs. The calculation of the financial ratios did not give rise to any difficulty, having all the available reclassified data of the income statements and the balance sheets from 2015 to 2022 (see Tables 1, 2 and 3):

Table 1. Simplified income statements from 2015 to 2017, 2018 budget and business plan from 2019 to 2022

\begin{tabular}{|c|c|c|c|c|c|c|c|c|}
\hline Income Statements & 2015 & 2016 & 2017 & 2018 & 2019 & 2020 & 2021 & 2022 \\
\hline Production & $€ 16,639,007$ & $€ 23,275,468$ & $€ 25,086,210$ & $€ 31,696,523$ & $€ 36,860,832$ & $€ 42,352,389$ & $€ 47,951,239$ & $€ 52,774,285$ \\
\hline Variable Costs & $€ 9,581,320$ & $€ 13,376,666$ & $€ 14,987,880$ & $€ 19,999,837$ & $€ 21,446,798$ & $€ 23,922,394$ & $€ 26,712,096$ & $€ 28,864,469$ \\
\hline Industrial Margin & $€ 7,057,687$ & $€ 9,898,802$ & $€ 10,098,330$ & $€ 11,696,686$ & $€ 15,414,034$ & $€ 18,429,995$ & $€ 21,239,143$ & $€ 23,909,816$ \\
\hline Fixed Costs & $€ 7,622,888$ & $€ 7,794,619$ & $€ 7,932,749$ & $€ 9,149,034$ & $€ 12,135,212$ & $€ 14,391,785$ & $€ 16,048,513$ & $€ 17,572,100$ \\
\hline EBIT or Operating Income & $€ 565,201$ & $€ 2,104,183$ & $€ 2,165,581$ & $€ 2,547,652$ & $€ 3,278,823$ & $€ 4,038,209$ & $€ 5,190,630$ & $€ 6,337,716$ \\
\hline Interest Expenses & $€ 603,565$ & $€ 143,288$ & $€ 112,293$ & $€ 176,970$ & $€ 172,590$ & $€ 122,943$ & $€ 68,612$ & $€ 46,828$ \\
\hline Net Profit & $€ 953,172$ & $€ 1,174,988$ & $€ 1,525,288$ & $€ 1,709,262$ & $€ 3,081,917$ & $€ 3,470,039$ & $€ 4,391,513$ & $€ 5,393,025$ \\
\hline
\end{tabular}


Many doubts have emerged in the calculation of the Degree of Operating Leverage (DOL). In the economic literature there are several definitions and calculation methods of the Operating Leverage, not always consistent, with different numerical values that have generated some doubts both from the theoretical and operative point of view. Damodaran (2001) and Brigham et al. (2011) use a DOL definition consistent with equation (1) whilst Horngren et al. (2001) adopt a definition consistent with equation (4). The numerical results obtainable are so different that the whole business case became confusing.

Table 2. Simplified balance sheets from 2015 to 2017, 2018 budget and business plan from 2019 to 2022

\begin{tabular}{|c|c|c|c|c|c|c|c|c|}
\hline Balance Sheets & 2015 & 2016 & 2017 & 2018 & 2019 & 2020 & 2021 & 2022 \\
\hline Cash & $€ 10,010,996$ & $€ 9,151,162$ & $€ 7,803,657$ & $€ 7,000,000$ & $€ 7,000,000$ & $€ 7,000,000$ & $€ 10,562,796$ & $€ 17,617,141$ \\
\hline Current Assets & $€ 15,075,229$ & $€ 16,588,111$ & $€ 22,774,098$ & $€ 23,628,025$ & $€ 25,501,123$ & $€ 27,745,167$ & $€ 28,433,328$ & $€ 29,701,799$ \\
\hline Inventories & $€ 5,009,553$ & $€ 7,282,782$ & $€ 10,809,655$ & $€ 11,713,906$ & $€ 12,466,890$ & $€ 13,447,761$ & $€ 14,117,451$ & $€ 14,507,026$ \\
\hline Acc. Payable \& Others Liab. & $-€ 9,621,845$ & $-€ 9,343,410$ & $-€ 14,596,025$ & $-€ 13,404,391$ & $-€ 15,680,920$ & $-€ 17,122,695$ & $-€ 18,487,854$ & $-€ 20,208,987$ \\
\hline Net Working Capital & $€ 5,453,384$ & $€ 7,244,701$ & $€ 8,178,073$ & $€ 10,223,634$ & $€ 9,820,202$ & $€ 10,622,473$ & $€ 9,945,474$ & $€ 9,492,811$ \\
\hline Fixed assets & $€ 4,677,249$ & $€ 4,611,318$ & $€ 5,250,641$ & $€ 7,016,705$ & $€ 9,025,169$ & $€ 11,076,074$ & $€ 11,861,501$ & $€ 10,371,113$ \\
\hline Other Liabilities & $€ 932,624$ & $€ 1,002,251$ & $€ 1,105,981$ & $€ 1,423,408$ & $€ 1,855,192$ & $€ 2,371,538$ & $€ 2,951,700$ & $€ 3,606,162$ \\
\hline Total Assets & $€ 19,209,005$ & $€ 20,004,930$ & $€ 20,126,390$ & $€ 22,816,931$ & $€ 23,990,180$ & $€ 26,327,009$ & $€ 29,418,071$ & $€ 33,874,903$ \\
\hline Equity & $€ 11,305,398$ & $€ 12,030,382$ & $€ 11,545,674$ & $€ 13,254,936$ & $€ 16,336,852$ & $€ 19,036,412$ & $€ 22,560,416$ & $€ 26,855,563$ \\
\hline Financial Long-Term Debt & $€ 1,541,863$ & $€ 1,637,864$ & $€ 3,747,467$ & $€ 5,639,649$ & $€ 5,822,946$ & $€ 6,100,340$ & $€ 6,857,656$ & $€ 7,019,341$ \\
\hline Financial Short-Term Debt & $€ 6,361,744$ & $€ 6,336,684$ & $€ 4,833,249$ & $€ 3,922,347$ & $€ 1,830,381$ & $€ 1,190,256$ & $€ 0$ & $€ 0$ \\
\hline Check & $€ 0$ & $€ 0$ & $€ 0$ & $-€ 0$ & $€ 0$ & $-€ 0$ & $-€ 0$ & $-€ 0$ \\
\hline NFP & $€ 2,107,389$ & $€ 1,176,614$ & $-€ 777,059$ & $-€ 2,561,996$ & $-€ 653,327$ & $-€ 290,596$ & $€ 3,705,140$ & $€ 10,597,800$ \\
\hline
\end{tabular}

All this made it necessary to carry out a supplementary investigation for the following reasons:

- initially the calculated DOL was so low to justify the observed empirical data, known and shared by the Top Management (Damodaran, 2001);

- later, by better analysing the company's profitability and using an ex-ante measure of the DOL, this latter reached such a high level that it could not be consistent with the observed situation (Horngren et al., 2012).

Based on these considerations, a sufficiently consolidated definition of Operating Leverage was sought as the ratio between the EBIT percentage variation and the Production percentage variation (Damodaran, 2001):

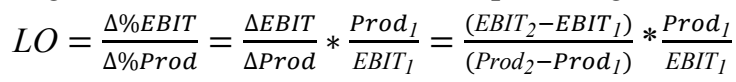

where:

$\Delta \% \mathrm{EBIT}=$ EBIT percentage variation between 2 periods;

$\triangle \mathrm{EBIT}=$ EBIT absolute variation between 2 periods;

$\mathrm{EBIT}_{\mathrm{n}}=\mathrm{EBIT}$ value in period $\mathrm{n}$;

$\Delta \%$ Prod $=$ Production percentage variation between 2 periods;

$\Delta$ Prod $=$ Production absolute variation between 2 periods;

$\operatorname{Prod}_{n}=$ Production value in period $n$.

Such a definition of DOL is an ex-post measure, since it measures what happened during the last period as the percentage variation compared to the previous period.

In addition, Revenues as a variable has been replaced by Production as a variable to take into account the investment in stock of work-in-progress since product Lead Times of the company under analysis are long, exceeding 120 days. It was considered that Production was more meaningful than Revenues in the specific case both from analytical and economic point of view. The definition of Operating Leverage highlighted in the equation (1) allows to reach a measure consistent with the values found in the business empirical life of the company under analysis.

A problem of another nature arises in this regard, only partially identifiable in equation (1): why a company with a sufficiently high industrial margin percentage, given by the difference between Production and Variable Costs, almost always above $40 \%$ from 2015 to 2022, does the Production increase not generate an EBIT increase to the point that justifies a development policy? What are the factors that determine a completely unsatisfactory dynamic of improving corporate profitability and how can they be measured?

We use equation (1) to analytically develop a relationship that highlights the potential variation of profitability, i.e. an ex-ante opportunity, with an ex-post result: 
where:

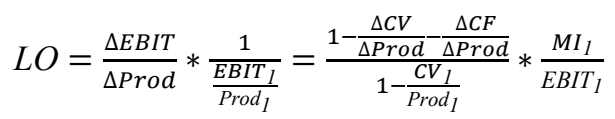

$\Delta$ Prod $=$ Production variation between 2 periods;

$\Delta \mathrm{CV}=$ Variable Costs variation between 2 periods;

$\Delta \mathrm{CF}=$ Fixed Costs variation between 2 periods;

$\mathrm{CV}_{1}=$ Variable Costs in period $1 ;$

$\mathrm{MI}_{1}=$ Industrial Margin in period 1, given by the difference between Production and Variable Costs.

Table 3. Some financial and performance ratios, financial statements from 2015 to 2017, 2018 budget and business plan from 2019 to 2022

\begin{tabular}{|c|c|c|c|c|c|c|c|c|}
\hline Ratios & 2015 & 2016 & 2017 & 2018 & 2019 & 2020 & 2021 & 2022 \\
\hline \multicolumn{9}{|l|}{ Financial Ratios } \\
\hline Equity Ratio & $58.9 \%$ & $60.1 \%$ & $57.4 \%$ & $58.1 \%$ & $68.1 \%$ & $72.3 \%$ & $76.7 \%$ & $79.3 \%$ \\
\hline Debt Ratio & $41.1 \%$ & $39.9 \%$ & $42.6 \%$ & $41.9 \%$ & $31.9 \%$ & $27.7 \%$ & $23.3 \%$ & $20.7 \%$ \\
\hline Financial Leverage & $69.9 \%$ & $66.3 \%$ & $74.3 \%$ & $72.1 \%$ & $46.8 \%$ & $38.3 \%$ & $30.4 \%$ & $26.1 \%$ \\
\hline Fixed Assets Coverage 1 & $241.7 \%$ & $260.9 \%$ & $219.9 \%$ & $188.9 \%$ & $181.0 \%$ & $171.9 \%$ & $190.2 \%$ & $258.9 \%$ \\
\hline Fixed Assets Coverage 2 & $274.7 \%$ & $296.4 \%$ & $291.3 \%$ & $269.3 \%$ & $245.5 \%$ & $226.9 \%$ & $248.0 \%$ & $326.6 \%$ \\
\hline Cash Ratio & $62.6 \%$ & $58.4 \%$ & $40.2 \%$ & $40.4 \%$ & $40.0 \%$ & $38.2 \%$ & $57.1 \%$ & $87.2 \%$ \\
\hline Quick Ratio & $125.6 \%$ & $117.7 \%$ & $101.7 \%$ & $109.2 \%$ & $114.4 \%$ & $116.3 \%$ & $134.6 \%$ & $162.4 \%$ \\
\hline Current Ratio & $156.9 \%$ & $164.2 \%$ & $157.4 \%$ & $176.8 \%$ & $185.6 \%$ & $189.7 \%$ & $210.9 \%$ & $234.1 \%$ \\
\hline \multicolumn{9}{|l|}{ Performance Ratios } \\
\hline Industrial Margin \% & $42.42 \%$ & $42.53 \%$ & $40.25 \%$ & $36.90 \%$ & $41.82 \%$ & $43.52 \%$ & $44.29 \%$ & $45.31 \%$ \\
\hline Cost/Income Ratio & $108.0 \%$ & $78.7 \%$ & $78.6 \%$ & $78.2 \%$ & $78.7 \%$ & $78.1 \%$ & $75.6 \%$ & $73.5 \%$ \\
\hline EBIT \% & $-3.4 \%$ & $9.0 \%$ & $8.6 \%$ & $8.0 \%$ & $8.9 \%$ & $9.5 \%$ & $10.8 \%$ & $12.0 \%$ \\
\hline EBITDA/NFP Ratio & $-9.4 \%$ & $-260.9 \%$ & $374.6 \%$ & $135.1 \%$ & $715.2 \%$ & $2096.3 \%$ & $-210.0 \%$ & $-84.8 \%$ \\
\hline Real Operating Leverage ${ }_{(\mathrm{t}+1)}$ & $-1184.1 \%$ & $37.5 \%$ & $67.0 \%$ & $176.1 \%$ & $155.5 \%$ & $215.9 \%$ & $219.7 \%$ & - \\
\hline Revenues Growth & $-5.7 \%$ & $31.7 \%$ & $5.2 \%$ & $30.5 \%$ & $16.2 \%$ & $15.1 \%$ & $13.8 \%$ & $10.6 \%$ \\
\hline Production Growth & n.a. & $39.9 \%$ & $7.8 \%$ & $26.4 \%$ & $16.3 \%$ & $14.9 \%$ & $13.2 \%$ & $10.1 \%$ \\
\hline EBIT Growth & n.a. & $-472.3 \%$ & $2.9 \%$ & $17.6 \%$ & $28.7 \%$ & $23.2 \%$ & $28.5 \%$ & $22.1 \%$ \\
\hline ROS & $-3.28 \%$ & $9.28 \%$ & $9.08 \%$ & $8.18 \%$ & $9.06 \%$ & $9.70 \%$ & $10.95 \%$ & $12.10 \%$ \\
\hline Total Assets Turnover & $89.6 \%$ & $113.3 \%$ & $118.5 \%$ & $136.4 \%$ & $150.8 \%$ & $158.2 \%$ & $161.1 \%$ & $154.7 \%$ \\
\hline ROI & $-2.9 \%$ & $10.5 \%$ & $10.8 \%$ & $11.2 \%$ & $13.7 \%$ & $15.3 \%$ & $17.6 \%$ & $18.7 \%$ \\
\hline Interest Expenses \% & $7.6 \%$ & $1.8 \%$ & $1.3 \%$ & $1.9 \%$ & $2.3 \%$ & $1.7 \%$ & $1.0 \%$ & $0.7 \%$ \\
\hline Financial Leverage & $69.9 \%$ & $66.3 \%$ & $74.3 \%$ & $72.1 \%$ & $46.8 \%$ & $38.3 \%$ & $30.4 \%$ & $26.1 \%$ \\
\hline Net Profit/EBT \% & $-81.6 \%$ & $59.9 \%$ & $74.3 \%$ & $72.1 \%$ & $99.2 \%$ & $88.6 \%$ & $85.7 \%$ & $85.7 \%$ \\
\hline ROE & $8.4 \%$ & $9.8 \%$ & $13.2 \%$ & $12.9 \%$ & $18.9 \%$ & $18.2 \%$ & $19.5 \%$ & $20.1 \%$ \\
\hline
\end{tabular}

Note. Real Operating Leverage is shifted by one year in the past.

From the previous equation (2), which algebraically elaborates the equation (1), it can be inferred that if there were no variations:

- $\quad$ of Fixed Costs, i.e. $\Delta \mathrm{CF}=0$;

- $\quad$ in the relationship between Variable Costs and Production in period 1 and 2;

the equation (2) would change in the following form:

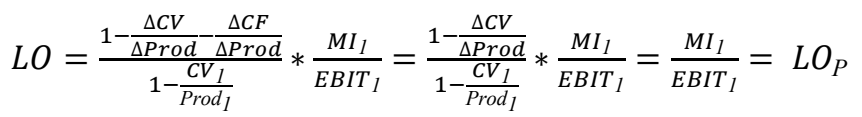

which can be called ex-ante or Potential Operating Leverage or $\mathrm{LO}_{\mathrm{p}}$.

This result is interesting because it highlights [see equation (3)] what the potential for the ex-ante EBIT variation is while equation (1) is an ex-post measure of the same phenomenon.

From now on we will call the first $\mathrm{LO}_{\mathrm{P}}$ and the second $\mathrm{LO}_{\mathrm{R}}$ to distinguish the ex-ante potential from the ex-post result:

$$
\begin{gathered}
L O_{P}=\frac{M I_{I}}{E B I T_{I}} \\
L O_{R}=\frac{\Delta \% E B I T}{\Delta \% \operatorname{Prod}}=L O_{P} * \frac{1-\frac{\Delta C V}{\Delta \text { Prod }^{\prime}}-\frac{\Delta C F}{\Delta \text { Prod }}}{1-\frac{C V_{I}}{\text { Prod }_{I}}}
\end{gathered}
$$

Summarizing: 
1) the Potential Operating Leverage $\mathrm{LO}_{\mathrm{P}}$ indicates the opportunity to achieve ex-ante an EBIT variation, given a certain Production variation. The $\mathrm{LO}_{\mathrm{P}}$ depends exclusively on conditions existing in the period preceding the company activities, not on actual or future conditions, since the ratio is dependent on two parameters of period 1;

2) the Real Operating Leverage $\mathrm{LO}_{\mathrm{R}}$ indicates the real EBIT percentage variation in comparison to the Production percentage variation and this result depends on how the management in period 2 will affect the starting economic conditions determined in period 1.

Let us examine the case we came across in summer 2018.

The data concern the financial period 2016 and 2017:

$$
\begin{gathered}
L O_{P}=\frac{M I_{2016}}{E B I T_{2016}}=470.4 \% \\
L O_{R}=\frac{\Delta \% E B I T_{2017 / 2016}}{\Delta \% \operatorname{Prod}_{2017 / 2016}}=37.5 \%
\end{gathered}
$$

Tables 1, 2, and 3 summarize the complete data of the business case.

The ratio between $\mathrm{LO}_{\mathrm{P}}$ and $\mathrm{LO}_{\mathrm{R}}$ is greater than 12 and this means that the ex-ante opportunity highlighted by $\mathrm{LO}_{\mathrm{P}}$ at the end of period 2016 has diminished approximately by $92 \%$ due to negative factors or variations determined in 2017.

Now comparing equation (4) to equation ( 1 bis) we can define the abatement factor $\alpha$ of the Potential Operating Leverage $\mathrm{LO}_{\mathrm{P}}$ in the following way:

$$
\alpha=\frac{L O_{P}}{L O_{R}}=\frac{1-\frac{C V_{I}}{\text { Prod }_{l}}}{1-\frac{\Delta C V}{\Delta \text { Prod }^{-}-\frac{\Delta C F}{\Delta \text { Prod }}}}
$$

Entering in equation (5) the values found in financial years 2016 and 2017, the following expression can be reached:

$$
\alpha=\frac{L O_{P}}{L O_{R}}=\frac{1-\frac{C V_{I}}{\text { Prod }_{l}}}{1-\frac{\Delta C V}{\Delta \text { Prod }}-\frac{\Delta C F}{\Delta \text { Prod }}}=\frac{1-57.471 \%}{(1-88.981 \%-7.628 \%)}=12.542
$$

Summarizing the company has captured a small share of the opportunity to increase EBIT or $1 / \alpha$, less than $8 \%$ wasting it about $92 \%$.

It is quite evident that the Variable Costs variation, as shown by empirical data, in comparison to the Production variation, $\Delta \mathrm{CV} / \Delta$ Prod, higher than $88 \%$ worsened the Industrial Margin in 2017 which fell from $42.53 \%$ to $40.25 \%$.

Now this result appears in part obvious: if the Industrial Margin shrinks, Break-even Point (BEP) shifts righthand and if the BEP's shift is greater than the Production increase, EBIT will worsen even though this shift is due also to the increase of Fixed Costs. We will devote a full paragraph to this topic hereinafter. From another point of view, we have to ask ourselves why an apparently modest $2.274 \%$ reduction in the Industrial Margin, accompanied by a slight increase of Fixed Costs, moved upward by only $1.772 \%$, could determine a strong containment of the EBIT variation and what the transmission mechanism is.

To identify the root causes, it will be necessary to isolate the fundamentals given by the unit prices, the unit variable costs, the quantity/mix of Production and the Fixed Costs, in short, the sets of variables that are normally analysed and provided by management accounting.

In the economic literature Sinha (2012) used the concept of an ex-ante and ex-post analysis of the DOL but his objective is to assess risk instead of measuring EBIT dynamic. Chiladze (2017) is bound to measure risk/opportunity deriving from the DOL concept based on several ratios, particularly the ratio between Fixed Costs and EBIT: he uses the ratio between Industrial Margin and EBIT also without realizing that it is an ex-ante measure of the DOL. Other Authors addressed the DOL analysis from different perspectives: Dugan et al. (1992), O'Brien et al. (1987) and Lord (1995) are oriented to investigate DOL estimation and interpretation, Alaghi (2012) correlates DOL to systematic risk in order to measure the effect on the companies listed in Teheran Stock Exchange. Lee (2009) uses DOL to assess operating risk of a high-tech company and his conclusion is interesting: "a manager can use the DOL to quickly estimate what impact various percentage changes in sales will have on profits, without the necessity of preparing detailed income statements.": I agree with him inside the framework I developed, that means we cannot forget price, cost and mix changes (or variations), sales change is not enough. Schönenberger (2014) developed an interesting framework to asses risk. He investigates Break-even Point (BEP) constancy with offsetting changes of Fixed and Variable Costs, assuming that "companies have no 
pricing power": that can be true but prices can be reduced even by the market and we cannot forget their impact on EBIT.

The question I had to answer was: why EBIT does not change consistently with Revenues growth? Does the fault lie on pricing or costing or both? How and to what extent? Industrial accounting gave me some good information about Revenues but no clue about Costing. On the other side economic literature was not useful to understand EBIT dynamic in order to answer the previous questions. I tried to develop a method to fill the research gap meanwhile answering the question with faulty information.

The methodology used was to move from absolute value to percentage variations by using the management accounting concept of variance analysis and modify the equation (1 bis) to achieve the transmission mechanism sought with the desired persuasive economic meaning.

The next steps will be oriented to fully explore some aspects on which perhaps no attention is paid: the analysis of the variations instead of values. What is relevant is not the absolute value of the Production, of the Variable and Fixed Costs but their variations in relation to each other. We will examine in sequence the variation of Production, Variable Costs, Industrial Margins, Fixed Costs and BEP's Quantity/Mix to summarize how all the variations put together can impact on the EBIT variation.

The paper can be considered punctilious, repetitive and redundant: my justification is that I would like to be very precise and check sometimes results from different perspectives in order to get always the same algebraic and numerical result and to guard against mistakes because it seems to me that I was sailing in uncharted water. I would like to apologize for that.

\section{Multi-Product Firms}

Before proceeding further, it will be necessary to consider that both the analysed firm and almost all the firms I have analysed or known or operative are multi-products. This must be taken into account and at the same time a methodology must be identified to allow the rigorous analytical treatment of the generic case with a simple but not simplified algebraic notation. In a multi-product firm, the Production or Revenues is given by the sum of the operative price multiplied by the quantities of each transaction of the period. The definition of transaction is to be preferred because different prices could be applied to the same product during each period. So we should define uselessly the Revenues/Production of the product $i$ as a further sum of the weighted average price multiplied by the quantity produced or sold during the year.

Consequently, Production (or Revenues) in period 1 is defined by the following equation:

$$
\operatorname{Prod}_{1}=\sum_{i=1}^{n}{ }_{i} p u_{1} *{ }_{i} q_{1}=p m_{1} * \sum_{i=1}^{n}{ }_{i} q_{1}=p m_{1} * q_{1}
$$

where:

$$
\begin{aligned}
& \operatorname{Prod}_{1}=\text { Production Value in period } 1 ; \\
& { }_{\mathrm{i}} \mathrm{pu}_{1}=\text { unit price of the transaction } i \text { in period } 1 ; \\
& \mathrm{i}_{1}=\text { quantity of the transaction } i \text { in period } 1 ; \\
& \mathrm{pm}_{1}=\text { weighted average price in period } 1 ; \\
& \mathrm{q}_{1}=\text { total quantity of the period } 1 .
\end{aligned}
$$

After some algebraic transformations we obtain that:

$$
\mathrm{pm}_{1}=\frac{\sum_{i=1}^{n}{ }_{i} \mathrm{pu}_{l^{*}}{ }_{i} q_{1}}{\sum_{i=1}^{n}{ }_{i} q_{1}}=\frac{\operatorname{Prod}_{1}}{q_{I}}
$$

From equation (7) it is easy to observe that the mix variation is dumped on the weighted average price and that makes it an unsuitable measure to accurately assess the unit price (or unit variable cost or unit industrial margin) variation. How to proceed?

We have to compute the variation of these measures between two periods. For instance, let us take Production and measure the percentage variation of quantities and weighted average prices from one period to the next:

$$
\Delta \% \operatorname{Prod}=\frac{\Delta \operatorname{Prod}_{1}}{\operatorname{Prod}_{1}}=\frac{p m_{2} * q_{2}-p m_{l} * q_{l}}{p m_{l_{1}} * q_{1}}=(1+\Delta \% p m) *(1+\Delta \% q)-1
$$

while equation (8) is solved by management accounting in the following way:

$$
\Delta \% \operatorname{Prod}=\Delta \% q+\Delta \% m p+\Delta \% p=(1+\Delta \% p m) *(1+\Delta \% q)-1
$$

where: 
$\Delta \% \mathrm{pm}=$ weighted average price percentage variation between two periods;

$\Delta \% \mathrm{q}=$ quantity percentage variance;

$\Delta \% \mathrm{mp}=$ mix percentage variance;

$\Delta \% \mathrm{p}=$ price percentage variance.

Now, through a simple algebraic transformation, we can use the sum of the quantity variance $\Delta \% \mathrm{q}$ and the mix variance $\Delta \% \mathrm{mp}$ to obtain a precise measurement of the total variation of quantity and mix $\Delta \%$ qmp given by the following relation:

where:

$$
\Delta \% q m p=\Delta \% q+\Delta \% m p
$$

$\Delta \% \mathrm{qmp}=$ quantity/mix percentage variation of Production between two periods.

Now the equation ( 8 bis) can be reprocessed in the following way:

$$
\Delta \% \operatorname{Prod}=\Delta \% q+\Delta \% m p+\Delta \% p=(1+\Delta \% p m) *(1+\Delta \% q)-1=(1+\Delta \% p u) *(1+\Delta \% q m p)-1
$$

Such a transformation allows to shift the mix variation from the weighted average prices $\Delta \% \mathrm{pm}$ to the quantity $\Delta \%$ qmp by introducing a new variable $\Delta \%$ pu that represents the percentage variations of unit price.

Using the equation ( 8 ter) we arrive at the following formulation of the value of $\Delta \%$ pu:

$$
\Delta \% p u=\frac{\Delta \% p}{(1+\Delta \% q m p)}=\frac{\Delta \% p m *(1+\Delta \% q)-\Delta \% m p}{(1+\Delta \% q m p)}
$$

Moreover, the expression in the equation ( 8 ter) referred to the binomial containing $\Delta \% \mathrm{pm}$ and $\Delta \% \mathrm{q}$ is equivalent to the expression referred to the binomial containing $\Delta \% \mathrm{pu}$ and $\Delta \% \mathrm{qmp}$; it follows that this formulation makes it possible to transform equation (6) into the following equivalent form:

$$
\operatorname{Prod}_{1}=\sum_{i=1}^{n}{ }_{i} p u_{1} *{ }_{i} q_{1}=p u_{1} * \sum_{i=1}^{n}{ }_{i} q_{1}=p m_{1} * q_{1}=p u_{1} * q m p_{1}
$$

where:

$$
\begin{aligned}
& \mathrm{pu}_{1}=\text { unit price mix independent in period } 1 ; \\
& \mathrm{qmp}_{1}=\text { quantity/mix in period } 1 .
\end{aligned}
$$

Mutatis mutandis, the same notations are also applicable to Variable Costs and Industrial Margins through the following relationships obtained by transformation:

where:

$$
\begin{gathered}
C V_{1}=\sum_{i=1}^{n}{ }_{i} \mathrm{cvu}_{1} *{ }_{i} q_{1}=\mathrm{cvm}_{1} * q_{1}=\mathrm{cvu}_{1} * q m c v_{1} \\
M I_{1}=\sum_{i=1}^{n}{ }_{i} \mathrm{miu}_{1} *{ }_{i} q_{1}=\mathrm{mim}_{1} * q_{1}=\mathrm{miu}_{1} * q m m i_{1}
\end{gathered}
$$

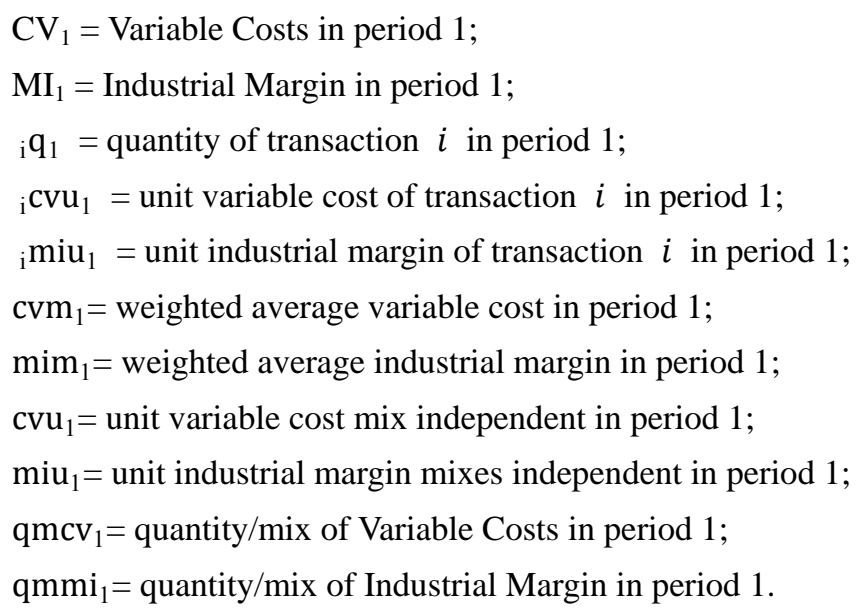

The preceding equations (6), (11) and (12) are simple notations that simplify the analytical treatment of any variation, that means unit price, unit variable cost, unit industrial margin and quantity/mix that we are going to analyse in the next paragraphs. It is useless to lug in the future analytical process summations that complicate the interpretation: better to replace them with their economic meaning. For more information, see Appendix A.

\section{Production Variation}

The determiners of Production variation (or Revenues) are given by the variation in quantities and mix on one 
side and unit prices on the other. In general, Production for a given period can be represented by the sum of Revenues coming from the transactions over the same period. From equation (6) we know that:

$$
\operatorname{Prod}_{1}=\sum_{i=1}^{n}{ }_{i} p u_{1} *{ }_{i} q_{l}=p u_{1} * q m p_{1}
$$

Now the Production percentage variation can be expressed as follows:

$$
\Delta \% \text { Prod }=\frac{\Delta \text { Prod }_{1}}{\text { Prod }_{1}}=\frac{p u_{2} * q m p_{2}-p u_{1} * q m p_{1}}{p u_{1} * q m p_{1}}=(1+\Delta \% p u) *(1+\Delta \% q m p)-1
$$

where:

$\Delta \% \mathrm{pu}=$ percentage variation mixes independent of unit prices $p u_{i}$ between two periods;

$\Delta \% \mathrm{qmp}=$ percentage variation of the quantity/mix of Production $q m p_{i}$ between two periods.

In a single-product firm the mix is zero, therefore there are no particular difficulties in determining the values of $\Delta \%$ pu and $\Delta \%$ qmp.

In the firm under analysis, since it is a multi-product company, it is necessary to separate exactly the percentage variation of unit prices, isolating it from the percentage variation of quantity and mix.

To achieve this result, management accounting must be used, because it can separate rigorously quantities, mix and price variances. Unfortunately, the result achieved by the management accounting is not immediately usable for the purposes we are aiming to. In fact, the equation (8) is solved by management accounting in the following way:

$$
\Delta \% \text { Prod }=\frac{\Delta \text { Prod }_{1}}{\text { Prod }_{l}}=\frac{\Delta Q . t y+\Delta \text { Mix }+\Delta \text { Price }}{\text { Prod }_{l}}=\Delta \% q+\Delta \% m p+\Delta \% p
$$

where the price variance $\Delta$ Price divided by the Production of period 1 is as follows:

$$
\Delta \% p=\frac{\Delta \text { Price }}{\text { Prod }_{1}}=\frac{\sum_{i=1}^{n}\left({ }_{i} p u_{2}-{ }_{i} p u_{1}\right) *{ }_{i} m_{2} * q_{2}}{\sum_{i=1}^{n} p u_{l^{*}} q_{1} q_{I}}=\frac{\left(p u_{2}-p u_{1}\right) * q m p_{2}}{p u_{I} * q m p_{1}}=\Delta \% p u *(1+\Delta \% q m p)
$$

In fact, the price variance does not measure only the percentage variation in the unit price between two periods since this variation contains an additional element represented by the percentage variation of quantity/mix that must be sterilized. We can easily reprocess the (13) by solving it for $\Delta \%$ pu:

$$
\Delta \% p u=\frac{\Delta \% p}{(1+\Delta \% q m p)}
$$

Therefore, the percentage variation of the quantity/mix $\Delta \% \mathrm{qmp}$ obtainable from the data of the management accounting is directly usable in the expression itself $\Delta \% \mathrm{qmp}$ while the term $\Delta \% \mathrm{pu}$ needs a simple reprocess.

It should be noted that the price variance $\Delta \% \mathrm{p}$ in the equation (13) will have to be calculated in a proper way in order to cancel the variance of the products rising in period 2, that means products not sold in period 1. In fact, rising products must determine only variances of quantity and mix and this is obtained by setting artificially the price of the rising products in period 1 at the same price as in period 2, even though they were not sold. With this trick, the price variance is cancelled and the variance is dumped in the quantity/mix variance. For products that have ceased, the price variance will always be zero as the quantity in period 2 is zero and no price variance will be detected.

We combine equations ( 8$)$ and ( 8 bis) in (8 ter):

$$
\Delta \% \operatorname{Prod}=\frac{\Delta \text { Prod }}{\text { Prod }_{1}}=\frac{\Delta Q . t y+\Delta \text { Mix }+\Delta \text { Price }}{\text { Prod }_{l}}=\Delta \% p u+\Delta \% p u * \Delta \% q m p+\Delta \% q m p
$$

from which we get that:

$$
\Delta \% p=\frac{\Delta \text { Price }}{\text { Prod }_{l}}=\Delta \% p u+\Delta \% p u * \Delta \% q m p=\Delta \% p u *(1+\Delta \% q m p)
$$

and

$$
\Delta \% q m p=\frac{\Delta Q \cdot t y+\Delta M i x}{\operatorname{Prod}_{1}}
$$

Let us examine the business case under analysis with the variations occurred in 2017 in comparison of 2016. We know that Production increased by $7.780 \%$; from management accounting data we find that there was a $9.397 \%$ increase in the quantity/mix variance. Consequently, the price variance will be the difference between the total variance of $7.780 \%$, decreased by the increase in the quantity/mix of $9.397 \%$ equal to a reduction of $1.617 \%$ 
which translates into a slight decrease in the unit price of $1.478 \%$. Please refer to (10) for the analytical definition that can be easily obtained from ( 8 ter):

$$
\Delta \% p u=\frac{\Delta \% \text { Prod }-\Delta \% q m p}{(1+\Delta \% q m p)}=\frac{7.780 \%-9.397 \%}{(1+9.397 \%)}=-1.478 \%
$$

In Table 4 we present the data coming from financial statements or budget or business plan and the values calculated using the equations that will be presented in the analysis. On the basis of these results we move on to examine the variation of the Variable Costs.

Table 4. Data and computed values of the variables depicted in the analysis

\begin{tabular}{|c|c|c|c|c|c|c|c|c|c|}
\hline Source & Variables & 2015 & 2016 & 2017 & 2018 & 2019 & 2020 & 2021 & 2022 \\
\hline datum & \%EBIT & $-3.397 \%$ & $9.040 \%$ & $8.633 \%$ & $8.038 \%$ & $8.895 \%$ & $9.535 \%$ & $10.825 \%$ & $12.009 \%$ \\
\hline datum & $\% \mathrm{cv}$ & $57.583 \%$ & $57.471 \%$ & $59.745 \%$ & $63.098 \%$ & $58.183 \%$ & $56.484 \%$ & $55.707 \%$ & $54.694 \%$ \\
\hline datum & $\% \mathrm{mi}$ & $42.417 \%$ & $42.529 \%$ & $40.255 \%$ & $36.902 \%$ & $41.817 \%$ & $43.516 \%$ & $44.293 \%$ & $45.306 \%$ \\
\hline datum & $\% c f$ & $45.813 \%$ & $33.489 \%$ & $31.622 \%$ & $28.864 \%$ & $32.922 \%$ & $33.981 \%$ & $33.468 \%$ & $33.297 \%$ \\
\hline datum & $\Delta \%$ Prod & & $39.885 \%$ & $7.780 \%$ & $26.350 \%$ & $16.293 \%$ & $14.898 \%$ & $13.220 \%$ & $10.058 \%$ \\
\hline datum & $\Delta \mathrm{CV} / \Delta$ Prod & & $57.189 \%$ & $88.981 \%$ & $75.820 \%$ & $28.018 \%$ & $45.080 \%$ & $49.826 \%$ & $44.627 \%$ \\
\hline datum & $\Delta \mathrm{CF} / \Delta$ Prod & & $2.588 \%$ & $7.628 \%$ & $18.400 \%$ & $57.823 \%$ & $41.092 \%$ & $29.590 \%$ & $31.590 \%$ \\
\hline datum & $\Delta \%$ pu & & $-2.972 \%$ & $-1.478 \%$ & $-2.249 \%$ & $0.593 \%$ & $-2.590 \%$ & $-7.000 \%$ & $-3.655 \%$ \\
\hline computed & $\Delta \% q m p$ & & $44.170 \%$ & $9.397 \%$ & $29.258 \%$ & $15.607 \%$ & $17.953 \%$ & $21.742 \%$ & $14.233 \%$ \\
\hline computed & $\Delta \%$ cvua & & $-3.162 \%$ & $2.421 \%$ & $3.236 \%$ & $-7.242 \%$ & $-5.434 \%$ & $-8.280 \%$ & $-5.406 \%$ \\
\hline computed & $\Delta \%$ miua & & $-2.715 \%$ & $-6.747 \%$ & $-10.390 \%$ & $13.990 \%$ & $1.368 \%$ & $-5.339 \%$ & $-1.452 \%$ \\
\hline computed & $\Delta \%$ EBIT & & $-472.289 \%$ & $2.918 \%$ & $17.643 \%$ & $28.700 \%$ & $23.160 \%$ & $28.538 \%$ & $22.099 \%$ \\
\hline datum & $\Delta \%$ EBIT & & $-472.289 \%$ & $2.918 \%$ & $17.643 \%$ & $28.700 \%$ & $23.160 \%$ & $28.538 \%$ & $22.099 \%$ \\
\hline computed & check & & $0.000 \%$ & $0.000 \%$ & $0.000 \%$ & $0.000 \%$ & $0.000 \%$ & $0.000 \%$ & $0.000 \%$ \\
\hline computed & $\mathrm{LO}_{\mathrm{p}}$ (on Production) & $-1248.7 \%$ & $470.4 \%$ & $466.3 \%$ & $459.1 \%$ & $470.1 \%$ & $456.4 \%$ & $409.2 \%$ & $377.3 \%$ \\
\hline computed & $\mathrm{LO}_{\mathrm{R}}$ (on Production) & & $-1184.1 \%$ & $37.5 \%$ & $67.0 \%$ & $176.1 \%$ & $155.5 \%$ & $215.9 \%$ & $219.7 \%$ \\
\hline computed & $\mathrm{LO}_{p}$ Abatement & & $-5.2 \%$ & $-92.0 \%$ & $-85.6 \%$ & $-61.6 \%$ & $-66.9 \%$ & $-52.7 \%$ & $-46.3 \%$ \\
\hline datum & $\Delta$ Prod & & $€ 6,636,461$ & $€ 1,810,742$ & $€ 6,610,313$ & $€ 5,164,309$ & $€ 5,491,556$ & $€ 5,598,850$ & $€ 4,823,046$ \\
\hline datum & $\Delta \mathrm{CV}$ & & $€ 3,795,346$ & $€ 1,611,214$ & $€ 5,011,957$ & $€ 1,446,961$ & $€ 2,475,596$ & $€ 2,789,702$ & $€ 2,152,373$ \\
\hline datum & $\Delta \mathrm{MI}$ & & $€ 2,841,115$ & $€ 199,528$ & $€ 1,598,356$ & $€ 3,717,348$ & $€ 3,015,961$ & $€ 2,809,148$ & $€ 2,670,673$ \\
\hline datum & $\Delta \mathrm{CF}$ & & $€ 171,731$ & $€ 138,130$ & $€ 1,216,286$ & $€ 2,986,177$ & $€ 2,256,574$ & $€ 1,656,728$ & $€ 1,523,586$ \\
\hline datum & $\Delta$ EBIT & & $€ 2,669,384$ & $€ 61,398$ & $€ 382,071$ & $€ 731,171$ & $€ 759,387$ & $€ 1,152,420$ & $€ 1,147,087$ \\
\hline datum & $\Delta \mathrm{MI} / \mathrm{MI}$ & & $40.256 \%$ & $2.016 \%$ & $15.828 \%$ & $31.781 \%$ & $19.566 \%$ & $15.242 \%$ & $12.574 \%$ \\
\hline datum & - $\Delta \mathrm{CF} / \mathrm{Ml}$ & & $-2.433 \%$ & $-1.395 \%$ & $-12.044 \%$ & $-25.530 \%$ & $-14.640 \%$ & $-8.989 \%$ & $-7.173 \%$ \\
\hline datum & $\Delta \mathrm{EBIT} / \mathrm{MI}$ & & $37.822 \%$ & $0.620 \%$ & $3.784 \%$ & $6.251 \%$ & $4.927 \%$ & $6.253 \%$ & $5.401 \%$ \\
\hline datum & $1 / \Delta \%$ Prod & & $250.721 \%$ & $1285.411 \%$ & $379.501 \%$ & $613.761 \%$ & $671.227 \%$ & $756.448 \%$ & $994.211 \%$ \\
\hline datum & $\Delta \% \mathrm{CF}$ & & $2.253 \%$ & $1.772 \%$ & $15.332 \%$ & $32.639 \%$ & $18.595 \%$ & $11.512 \%$ & $9.494 \%$ \\
\hline computed & $\triangle \% \mathrm{BEP}$ & & $5.107 \%$ & $9.136 \%$ & $28.705 \%$ & $16.360 \%$ & $16.995 \%$ & $17.801 \%$ & $11.107 \%$ \\
\hline
\end{tabular}

\section{Variable Costs Variation}

The determiners of the Variable Costs are given by the variations in quantity/mix and unit variable costs also. To make the dissertation sufficiently simple, we will not include manufacturing inefficiencies such as wasted materials, machine downtime, training, non-compliance, etc. in the equations. Moreover, we introduce a strong hypothesis consisting in calculating the Total Variable Costs $\mathrm{CV}_{\mathrm{i}}$ of the period $i$ as the sum of the unit variable costs ascribable to each single product multiplied by the quantity manufactured instead as the sum of the cost of any single productive factors multiplied by the quantity used in the manufacturing process. This simplification on one side would seem to introduce a distortion in the analysis of Variable Costs but after all it does not prove to be such distortive and it serves simply to equate the quantities to which both $\operatorname{Prod}_{1}$ and $\mathrm{CV}_{1}$ refer. The consequence is that the manufacturing inefficiencies cannot increase $q_{i}$ because these are not the quantities of the productive factors used in the manufacturing process, so they must be fully dumped on the value of the unit variable cost $\mathrm{cvu}_{\mathrm{i}}$.

We define the Variable Costs variation in respect to the Production variation in the following way:

$$
\frac{\Delta C V}{\Delta \operatorname{Prod}}=\frac{\sum_{i=1}^{n}{ }_{i} c v u_{2}{ }_{i} q_{2}-\sum_{i=1}^{p}{ }_{i} c v u_{I^{*}} q_{I}}{\sum_{i=1}^{n}{ }_{i} p u_{2}{ }_{i} q_{2}-\sum_{i=1}^{p}{ }_{i} p u_{I^{*}}{ }_{i} q_{I}}=\frac{C V_{I}}{\operatorname{Prod}_{I}} * \frac{[(1+\Delta \% c v u) *(1+\Delta \% q m c v)-1]}{[(1+\Delta \% p u) *(1+\Delta \% q m p)-1]}
$$

where:

$\Delta \% \mathrm{cvu}=$ percentage variation of the unit variable costs $\mathrm{cvu}_{\mathrm{i}}$ between two periods;

$\Delta \% \mathrm{qmcv}=$ percentage variation of the quantity/mix of Variable Costs $\mathrm{qmcv}_{\mathrm{i}}$ between two periods.

Now the only variable not known in equation (14) is just $\Delta \%$ cvu, easily obtainable with few simple algebraic passages. As a matter of fact, $\Delta \mathrm{CV} / \Delta$ Prod ratio can be obtained from the company financial statements (see Table 4.) while the terms $\Delta \% \mathrm{qmp}$ and $\Delta \% \mathrm{pu}$ can be obtained from Production variation presented in the previous paragraph while $\Delta \% \mathrm{qmcv}$ will be set equal to $\Delta \% \mathrm{qmp}$. The variable $\Delta \% \mathrm{cvu}$ can be obtained as the unknown quantity from equation (14) without any need to resort to management accounting data provided that 
$\Delta \%$ qmcv will be equal to $\Delta \% \mathrm{qmp}$ :

$$
\Delta \% c v u=\frac{C V_{2}}{C V_{1}} * \frac{1}{(1+\Delta \% q m c v)}-1
$$

The result achieved is important as it allows to reach an estimate of the percentage variation of the unit variable costs $\Delta \%$ cvu through an analytical way, without having the need to carry out complicated analysis on the trend of manufacturing costs or purchasing costs of productive factors and, if the result achieved is considered reasonable, it allows to make decisions in the acquisition and use of productive factors. From equation (15) it is clear that:

$$
\frac{C V_{2}}{C V_{1}}=(1+\Delta \% c v u)(1+\Delta \% q m c v)
$$

as expected as for Production, it is obtained that the percentage variation of the Total Variable Costs is given by the following algebraic reprocess:

$$
\Delta \% C V=\frac{\Delta C V}{C V_{l}}=(1+\Delta \% c v u)(1+\Delta \% q m c v)-1=(1+\Delta \% c v u a)(1+\Delta \% q m p)-1
$$

where:

$\Delta \%$ cvua $=$ approximate percentage variation of the unit variable costs $\mathrm{cvu}_{\mathrm{i}}$ between two periods;

Now it can be defined the relationship between $\Delta \% \mathrm{cvu}$ and $\Delta \%$ cvua:

$$
\Delta \% c v u a=\frac{(1+\Delta \% c v u) *(1+\Delta \% q m c v)}{(1+\Delta \% q m p)}-1=\Delta \% c v u-\varepsilon m p c v * \frac{(1+\Delta \% c v u)}{(1+\Delta \% q m p)}
$$

where:

$\varepsilon m p c v=$ difference between the percentage variations of Production Mix and Variable Costs Mix being (see Appendix A):

$$
\varepsilon m p c v=\Delta \% m p-\Delta \% m c v=(1+\Delta \% q) *\left(\rho p_{1}-\rho c v_{1}\right)
$$

By setting erroneously that $\varepsilon \mathrm{mpcv}$ be nil or negligible, a share of the percentage variation of the Variable Costs Mix will be shifted to $\Delta \%$ cvua from $\Delta \% \mathrm{qmcv}$ but the percentage variation of the Total Variable Costs remains unchanged.

The previous analysis it would lead us to conclude, perhaps too quickly, that management accounting is useful only for Revenues and Production, serving little or nothing for Variable Costs. Actually, this result has been achieved through some simplifications that unload any deviation from the manufacturing standard to unit variable costs $\mathrm{Cvu}_{\mathrm{i}}$ and by supposing that Production Mix and Variable Costs Mix are not too much dissimilar.

At the moment this conclusion appears to be sufficient in the absence of more information from management accounting. In the business case under analysis, using equation (18), a value of $\Delta \%$ cvua is reached corresponding to an increase of $2.421 \%$ from 2016 to 2017 :

$$
\Delta \% \text { cvua }=\frac{C V_{2}}{C V_{l}} * \frac{1}{(1+\Delta \% q m p)}-1=\frac{112.045 \%}{(1+9.397 \%)}-1=2.421 \%
$$

The latter result was obtained by setting $\Delta \% \mathrm{qmcv}$ equal to $\Delta \% \mathrm{qmp}$ (see Appendix $\mathrm{A}$ for an in-depth analysis).

\section{Industrial Margin Variation}

Now we must complete the analysis by considering the Industrial Margin variation as a simple difference between the values it assumes in period 2 in comparison to period 1 , according to the variables $\Delta \% \mathrm{pu}$ and $\Delta \%$ cvu just introduced.

To obtain this result it is not sufficient to calculate the difference between $\Delta \% \mathrm{pu}$ and $\Delta \% \mathrm{cvu}$, it is necessary to develop an equation starting from the difference between the Industrial Margins $\% \mathrm{mi}_{\mathrm{i}}$ of two periods by using the equations (6) and (11):

$$
\begin{gathered}
\Delta \% m i=\% m i_{2}-\% m i_{1}=\frac{M I_{2}}{\operatorname{Prod}_{2}}-\frac{M I_{1}}{\operatorname{Prod}_{1}}=\frac{p u_{2} * q m p_{2}-c v u_{2} * q m c v_{2}}{p u_{2} * q m p_{2}}-\frac{p u_{1} q m p_{2}-c v u_{1} * q m c v_{1}}{p u_{1} * q m p_{1}}= \\
=\frac{C V_{1}}{\text { Prod }_{1}} *\left[1-\frac{(1+\Delta \% c v u)}{(1+\Delta \% p u)} * \frac{(1+\Delta \% q m c v)}{(1+\Delta \% q m p)}\right]
\end{gathered}
$$

where:

\footnotetext{
$\Delta \% \mathrm{mi}=$ difference of the industrial margin percentage $\% \mathrm{mi}_{\mathrm{i}}$ between two periods;

$\% \mathrm{mi}_{\mathrm{i}}=$ industrial margin percentage $\% \mathrm{mi}_{\mathrm{i}}$ in period $i$;

$\mathrm{MI}_{\mathrm{i}}=$ Industrial Margin in period $i$.
} 
Now the equation (19) highlights the relationship that links the difference of the industrial margin percentage between two periods depending on $\Delta \% \mathrm{pu}$ and $\Delta \% \mathrm{cvu}$; in this way we obtain a radically different result from the simple difference between the two variables $\Delta \% \mathrm{pu}$ and $\Delta \% \mathrm{cvu}$ and dependent on the percentage variations of Production Mix $\Delta \% \mathrm{mp}$ and Variable Costs Mix $\Delta \% \mathrm{mcv}$. Even though there are significant differences between Production Mix and Cost Variable Mix, it will be possible to simplify the previous equation (19) in the following way finding a result independent from any Quantity percentage variation:

$$
\begin{aligned}
& \Delta \% m i=\% m i_{2}-\% m i_{1}=\frac{C V_{I}}{\text { Prod }_{I}} *\left[1-\frac{(1+\Delta \% c v u)}{(1+\Delta \% p u)} * \frac{(1+\Delta \% q m c v)}{(1+\Delta \% q m p)}\right]= \\
= & \frac{C V_{I}}{\text { Prod }_{I}} *\left[1-\frac{(1+\Delta \% c v u a)}{(1+\Delta \% p u)} * \frac{(1+\Delta \% q m p)}{(1+\Delta \% q m p)}\right]=\frac{C V_{I}}{\text { Prod }_{I}} *\left[1-\frac{(1+\Delta \% c v u a)}{(1+\Delta \% p u)}\right]
\end{aligned}
$$

In the case of the company under analysis, using (20), a value of $\Delta \%$ mi equal to $-2.274 \%$ is reached, that means a reduction from 2016 to 2017 :

$$
\Delta \% m i=\% m i_{2}-\% m i_{1}=\frac{C V_{I}}{\text { Prod }_{1}} *\left[\frac{(\Delta \% p u-\Delta \% c v u)}{(1+\Delta \% p u)}\right]=57.471 \% *\left[\frac{-1.478 \%-2.421 \%}{(1-1.478 \%)}\right]=-2.274 \%
$$

which exactly corresponds to the difference between the industrial margin percentage reduced to $40.255 \%$ from $42.529 \%$.

For the purpose of further analysis, it will be useful to highlight also the equation that originates $\Delta \% \mathrm{mi} \%$ as a ratio rather than the difference between the industrial margin percentage of two periods:

$$
\Delta \% m i \%=\frac{\% m i_{2}}{\% m i_{1}}=\frac{M I_{2}}{\text { Prod }_{2}} * \frac{\operatorname{Prod}_{1}}{M I_{1}}=\frac{m i u_{2} * q m m i_{2}}{p u_{2} * q m p_{2}} * \frac{p u_{1} * q m p_{1}}{m i u_{1} * q m m i_{1}}=\frac{(1+\Delta \% m i u)}{(1+\Delta \% p u)} *\left[1-\frac{\varepsilon m p m i}{(1+\Delta \% q m p)}\right]
$$

where:

$\Delta \% \mathrm{mi} \%=$ percentage ratio of the industrial margin percentage between two periods;

$\Delta \%$ miu $=$ percentage variation of the unit industrial margin $\mathrm{miu}_{\mathrm{i}}$ between two periods;

$\operatorname{miu}_{\mathrm{i}}=$ unit industrial margin in period $i$;

$\varepsilon m p m i=$ difference between the percentage variations of Production Mix and Industrial Margin Mix.

By supposing that $\varepsilon$ mpmi be nil or negligible, the equation (21) can be simplified in the following (21 bis):

$$
\Delta \% m i \%=\frac{\% m i_{2}}{\% m i_{1}}=\frac{(1+\Delta \% m i u)}{(1+\Delta \% p u)} *\left[1-\frac{\varepsilon m p m i}{(1+\Delta \% q m p)}\right] \simeq \frac{(1+\Delta \% m i u)}{(1+\Delta \% p u)}
$$

The latter relationship is apparently mix independent, namely the percentage variation of the quantity/mix $\Delta \% \mathrm{qmp}$ and $\Delta \% \mathrm{qm} c \mathrm{v}$, and this will become clearer in the paragraph that will deal with the Break-even Point variation. For the time being it is enough to specify that if the Industrial Margin percentage will shrink from 10\% to $8 \%$, the variation obtained as a difference is only $-2 \%$ while the ratio would be $80 \%$.

It should also be noted that both $\mathrm{miu}_{\mathrm{i}}$ and $\Delta \%$ miu are not known variables but thanks to (21) we can determine the value of $\Delta \%$ miu as a function of the other variables already known:

$$
\Delta \% m i u=\frac{\% m i_{2}}{\% m i_{1}} *(1+\Delta \% p u) \frac{(1+\Delta \% q m p)}{(1+\Delta \% q m m i)}-1=\frac{\% m i_{2}}{\% m i_{1}} * \frac{(1+\Delta \% p u)}{\left[1-\frac{\varepsilon m p m i}{(1+\Delta \% q m p)}\right]}-1
$$

In the case of the company under analysis, having supposed that empmi be nil or negligible, we obtain an approximated value of $\Delta \%$ miu that can be defined $\Delta \%$ miua:

$$
\Delta \% \text { miua }=\frac{\% m i_{2}}{\% m i_{1}} *(1+\Delta \% p u)-1=\frac{40.255 \%}{42.529 \%} *(1-1.478 \%)-1=-6.747 \%
$$

where:

$\Delta \%$ miua $=$ approximate percentage variation of the unit industrial margin $\mathrm{miu}_{\mathrm{i}}$ between two periods.

The approximated percentage variation of the unit industrial margin is negative by $6.747 \%$, value that also relies on the Mix error empmi.

\section{Fixed Costs Variation}

The variation of Fixed Costs compared to the Production variation is relatively simple to analyse:

$$
\frac{\Delta C F}{\Delta \text { Prod }}=\frac{C F_{2}-C F_{1}}{p u_{2} * q m p_{2}-p u_{1} * q m p_{1}}=\frac{C F_{1}}{\operatorname{Prod}_{1}} * \frac{\Delta \% C F}{[(1+\Delta \% p u) *(1+\Delta \% q m p)-1]}
$$

where:

$\mathrm{CF}_{\mathrm{i}}=$ Fixed Costs in period $i$;

$\Delta \% \mathrm{CF}=$ percentage variation of Fixed Costs between two periods. 
All the variables of equation (23) are known because they can be easily got from the company's financial statements. In the case of the company under analysis the $\Delta \mathrm{CF} / \Delta$ Prod ratio is equal to $7.628 \%$ in the transition from 2016 to 2017.

The condition that Fixed Costs are immutable to Production variation is unrealistic. The existence of a long-term relationship between the increase of Production and the growth of Fixed Costs, either as a monolithic entity or in its individual components properly classified and grouped together, should be analysed more carefully.

An alternative approach could evaluate a constant ratio of the Fixed Costs in respect of Production in two periods, that means $\Delta \mathrm{CF} / \Delta$ Prod, by calculating the variation of the Fixed Costs in the period 2 with respect to this objective. Let us imagine that we wish to define the regularity of the relationship between Fixed Costs and Production in period 1 and 2 as a pursuable business objective. The constancy of this relationship translates into the following condition that can be expressed with equation (24):

$$
\frac{C F_{1}}{\operatorname{Prod}_{1}}=\frac{C F_{2}}{\operatorname{Prod}_{2}}=\% c f
$$

where:

$\% c f=$ ratio of Fixed Costs on Production, constant in two periods.

From (24) follows that:

$$
\frac{C F_{2}}{\text { Prod }_{2}}-\frac{C F_{1}}{\text { Prod }_{1}}=\frac{C F_{1}}{\text { Prod }_{1}} *\left(\frac{C F_{2}}{\text { Prod }_{2}} \frac{\operatorname{Prod}_{1}}{C F_{1}}-1\right)=\% c f *\left(\frac{1+\Delta \% C F}{1+\Delta \% \text { Prod }}-1\right)=0
$$

from which it follows that the condition to get a $\% c f$ ratio constant over time, the following condition must be met:

$$
\frac{(1+\Delta \% C F)}{(1+\Delta \% \text { Prod })}-1=0
$$

Such a condition is achieved when the percentage variation of Fixed Costs is equal to the percentage increase of Production from which we obtain the general condition (25):

$$
\Delta \% C F=\Delta \% \operatorname{Prod}
$$

By developing the equation (25) we obtain the following additional conditions:

$$
\begin{gathered}
\frac{\Delta C F}{C F_{1}}=\frac{\Delta \text { Prod }_{1}}{\text { Prod }_{I}} \\
\frac{\Delta C F}{\Delta \text { Prod }}=\frac{C F_{I}}{\text { Prod }_{1}}=\% c f
\end{gathered}
$$

In order to keep $\% c f$ ratio constant over different periods, it is necessary that the percentage variation of Fixed Costs $\Delta \% \mathrm{CF}$ remains equal to the percentage increase of Production $\Delta \%$ Prod and consequently that the ratio between the increase of Fixed Costs and the increase of Production is equal to the $\% c f$ ratio.

\section{Break-even Point Variation}

The Break-even Point or, more briefly BEP, is defined as the quantity of Production necessary to reach a balance between the value of the Production and the total amount of Variable Costs and Fixed Costs of the company, bringing EBIT to zero.

Analytically this means:

$$
\left(\operatorname{Prod}_{i}-C V_{i}\right)-C F_{i}=E B I T_{i}=0
$$

Using the algebraic notation so far used for multi-product firms, equation (26) is transformed into the following equation:

$$
m i u_{i} * q m m i_{i}-C F_{i}=0
$$

which represents the equilibrium in period $i$.

Solving the equation (26 bis) for the unknown variable $\mathrm{qmmi}_{\mathrm{i}}$, that is the variable that represents the quantity/mix of the Industrial Margin, we get the break-even value:

$$
q m m i_{i}=\frac{C F_{i}}{m i u_{i}}={ }_{B E P} q m m i_{i}
$$

where:

${ }_{\mathrm{BEP}} \mathrm{qmmi}_{\mathrm{i}}=$ break-even quantity/mix of the Industrial Margin in period $i$;

$\mathrm{CF}_{\mathrm{i}}=$ Fixed Costs in period $i$. 
Let us now pass to the calculation of the BEP variation between two periods; we define BEP variation $\triangle \% B E P$ in the following way:

$$
\Delta \% B E P(q m m i)=\frac{B_{B E P} q m m i_{2}-{ }_{B E P} q m m i_{1}}{{ }_{B E P} q m m i_{1}}=\frac{(\Delta \% C F-\Delta \% m i u)}{(1+\Delta \% m i u)}
$$

The result obtained is interesting since it directly links the percentage variation of $\triangle \% B E P$ to the percentage variation of Fixed Costs $\Delta \% \mathrm{CF}$ and unit industrial margin $\Delta \%$ miu: an increase in Fixed Costs must be offset by an equivalent percentage increase in Industrial Margins to neutralize the increase in BEP. The increase in Industrial Margins acts as a brake in the variation of the BEP while their reduction acts as a multiplier.

In the business case under analysis the BEP percentage variation is given by the following:

$$
\Delta \% B E P(q m m i)=\frac{(\Delta \% C F-\Delta \% \text { miua })}{(1+\Delta \% \text { miua })}=\frac{1.772 \%-(-6.747 \%)}{(1-6.747 \%)}=+9.135 \%
$$

The approximated BEP variation $\triangle \% \mathrm{BEP}(\mathrm{qmmi})$ was $9.135 \%$, i.e. lower than the increase in Production of $9.397 \%$ measured as a quantity/mix variance $\Delta \%$ qmp. Consequently, a slight increase in EBIT is to be expected, which in fact has increased by $2.918 \%$ but reduced as a percentage in respect to Production.

Figure 1 (not to scale) summarizes the BEP variation occurred between 2016 and 2017.

From an economic perspective, it can be observed that the increase of BEP is caused by:

- a strong increase in Fixed Costs with BEP moving from point A to point B;

- a strong increase in unit variable costs which shifts BEP to point $\mathrm{C}$ and

- a slight reduction in unit prices with BEP shifting to point $\mathrm{D}$

determining a shrinkage of the industrial margin percentage from $\% \mathrm{mi}_{1}$ to $\% \mathrm{mi}_{2}$.

The cumulative effect is to increase BEP by over $9 \%$. In the next section will be analysed in detail the impact that all the variations so far analysed determine individually and jointly on EBIT.

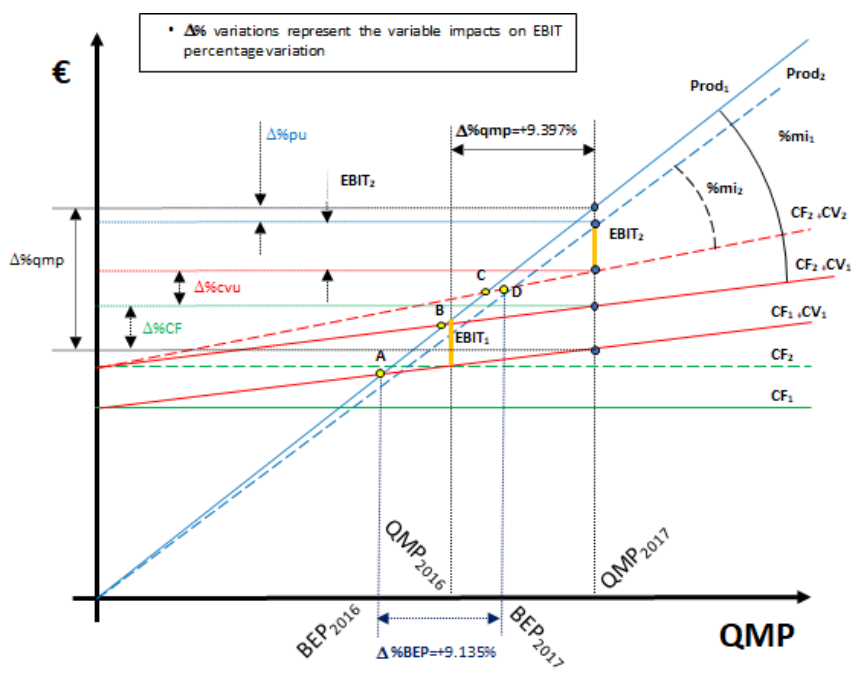

Figure 1. BEP variation between 2016 and 2017

\section{EBIT Variation}

After having examined the variations of Production, Variable Costs and Fixed Costs, let us examine how all the previous variations impact on the EBIT variation. The variation will be examined as a percentage variation between two periods to determine at the end of the analysis how it may affect the degree of the ex-post Operating Leverage:

$$
\Delta \% E B I T=\frac{E B I T_{2}-E B I T_{I}}{E B I T_{I}}=\frac{\operatorname{Prod}_{I} *[(1+\Delta \% p u) *(1+\Delta \% q m p)-1]-C V_{I} *[(1+\Delta \% c v u) *(1+\Delta \% q m c v)-1]-C F_{1} * \Delta \% C F}{E B I T_{l}}
$$

where all the variables here represented have been examined in the previous paragraphs already. Equation (29) highlights the determiners of the EBIT percentage variation as the percentage variations of parameters determined in the previous period, i.e. $\operatorname{Prod}_{1}, \mathrm{CV}_{1}, \mathrm{CF}_{1}$ and $\mathrm{EBIT}_{1}$, to which are applied the variations that are briefly summarized below: 
- $\Delta \% \mathrm{pu}=$ percentage variation of unit price $\mathrm{pu}_{\mathrm{i}}$ between two periods;

- $\Delta \% \mathrm{qmp}=$ percentage variation of quantity/mix of Production $\mathrm{qmp}_{\mathrm{i}}$ between two periods;

- $\Delta \% \mathrm{qmcv}=$ percentage variation of quantity/mix of Variable Costs $\mathrm{qmcv}_{\mathrm{i}}$ between two periods;

- $\Delta \% \mathrm{cvu}=$ percentage variation of the unit variable cost of $\mathrm{cvu}_{\mathrm{i}}$ between two periods;

- $\Delta \% \mathrm{CF}=$ percentage variation of Fixed Costs $\mathrm{CF}_{\mathrm{i}}$ between two periods.

From equation (29) it can be pointed out that even modest variations of unit prices and unit variable costs could determine significant EBIT variations if they are matched by a substantial increase in the quantity/mix $\Delta \% q m p$ and $\Delta \% \mathrm{qmcv}$, and such variations are all the more disturbing as they more produce a negative impact on EBIT as in the case of a simultaneous $\Delta \% \mathrm{pu}$ reduction and $\Delta \% \mathrm{cvu}$ increase because the increases of quantity/mix act as multipliers on them.

In essence, EBIT percentage variation is influenced by:

- $\quad$ starting parameters determined in period 1 and

- $\quad$ percentage variations of variables occurred and/or planned in period 2.

What is the advantage of this representation?

It instantly highlights where Top Management must intervene to maximize EBIT, whatever in a company belonging to any industry under development or in a company that has to defend a dominant market position.

The income statement simply represents two positions or ship's points evaluated 12 months apart but nothing tells us about the real course the company-ship has followed in the last 12 months even though income statement is obtained by quantities considered flows. The informational content of equation (29) in its final form is higher than the following equation (29 bis), completely equivalent but less explanatory in terms of business management content:

$$
\Delta \% E B I T=\frac{E B I T_{2}-E B I T_{1}}{E B I T_{l}}=\frac{\Delta E B I T}{E B I T_{l}}=\frac{\Delta P r o d-\triangle C V-\triangle C F}{E B I T_{l}}
$$

Equation (29 bis) is the representation of what can be inferred from a corporate income statement, while (29) explains in detail, especially form Production (or Revenues) and Variable Costs perspective, the determiners of EBIT variation, variables whose values very seldom are present in the reports supporting the company's financial statements. Certainly, to get all the data in the equation (29) many information are needed, available only internally and not always disclosed to the third parties outside the company.

Without any willpower to examine in detail which policy is to be pursued in the various stages of the Business or Company life cycle, it seems likely that a company in a rapidly growing market or business will try to act mainly on prices and quantities/mix to positively affect EBIT, not fearing a margin shrink by having a relatively low initial Production $\operatorname{Prod}_{1}$. The opposite will happen for a market leader that will aim to curb unit variable costs and/or Fixed Costs to offset a reduction in unit prices and/or quantities/mix.

Now we can examine how the previous individual percentage variations influence the EBIT percentage variation. Let us consider the partial derivatives of the EBIT percentage variation with respect to any single variation:

$$
\begin{gathered}
\frac{\partial \Delta \% E B I T}{\partial \Delta \% p u}=\frac{\text { Prod }_{I}}{E B I T_{l}} *(1+\Delta \% q m p) \\
\frac{\partial \Delta \% E B I T}{\partial \Delta \% c v u}=-\frac{C V_{I}}{E B I T_{l}} *(1+\Delta \% q m c v) \\
\frac{\partial \Delta \% E B I T}{\partial \Delta \% q m p}=\frac{\text { rrod }_{l}}{E B I T_{1}} *(1+\Delta \% p u) \\
\frac{\partial \Delta \% E B I T}{\partial \Delta \% q m c v}=-\frac{C V_{I}}{E B I T_{l}} *(1+\Delta \% c v u) \\
\frac{\partial \Delta \% E B I T}{\partial \Delta \% C F}=-\frac{C F_{I}}{E B I T_{l}} \\
\frac{\partial \Delta \% E B I T}{\partial \Delta \% q m}=L O_{P}+\frac{\operatorname{Prod}_{l} * \Delta \% p u-C V_{l} * \Delta \% c v u}{E B I T_{I}}
\end{gathered}
$$

From the previous equations it can be pointed out that the sensitivity of EBIT percentage variation $\triangle \% \mathrm{EBIT}$ is greater, except in an economically ruinous context, compared to the unit prices variation $\Delta \%$ pu since the numerator is the greatest of the 6 partial derivatives, having all the same denominator.

Moreover, from the equations (30) to (33) it is necessary to set the non-differential terms to zero to fully evaluate the sensitivity of the EBIT percentage variation in respect to the differential term. 
Substantially in (30) and (31) the non-differential variables $\Delta \% \mathrm{qmp}$ and $\Delta \% \mathrm{qmcv}$ act as accelerators when greater than zero, while in (34), since there is no differential term, there would be a direct impact on $\Delta \%$ EBIT. The most interesting sensitivity is the equation (35): if there are no variations of unit prices and unit variable costs and the difference between $\Delta \% \mathrm{qmp}$ and $\Delta \% \mathrm{qmcv}$, approximated to $\Delta \% \mathrm{qm}$, is negligible, the EBIT percentage variation $\Delta \%$ EBIT is influenced by the ex-ante Operating Leverage whereas the non-differential terms $\Delta \%$ pu and $\Delta \% \mathrm{cvu}$ act to abate the ex-ante Operative Leverage effect when they are respectively negative and positive.

The economic consequences are interesting: in companies with a low incidence of Total Variable Costs they can neglect their containment, which instead will become central in companies with a high incidence of them.

In the specific case under analysis, it should be pointed out that all the sensitivities change every year but taking into consideration the period from 2016 or 2022, the sensitivity hierarchy does not change: in the first place we will have the sensitivity to $\Delta \% \mathrm{pu}$ and $\Delta \% \mathrm{qmp}$, in second $\Delta \% \mathrm{cvu}$ and $\Delta \% \mathrm{qmcv}$, in third $\Delta \% \mathrm{qm}$ and at last $\Delta \%$ CF (see Table 5).

Table 5. Sensitivity coefficients from 2015 to 2022

\begin{tabular}{rrrrrrrrr}
\hline Sensitivity Coefficients & $\mathbf{2 0 1 5}$ & $\mathbf{2 0 1 6}$ & $\mathbf{2 0 1 7}$ & $\mathbf{2 0 1 8}$ & $\mathbf{2 0 1 9}$ & $\mathbf{2 0 2 0}$ & $\mathbf{2 0 2 1}$ & $\mathbf{2 0 2 2}$ \\
\hline Prod/EBIT & -29.44 & 11.06 & 11.58 & 12.44 & 11.24 & 10.49 & 9.24 & 8.33 \\
-CV/EBIT & 16.95 & -6.36 & -6.92 & -7.85 & -6.54 & -5.92 & -5.15 & -4.55 \\
MI/EBIT & -12.49 & 4.70 & 4.66 & 4.59 & 4.70 & 4.56 & 4.09 & 3.77 \\
-CF/EBIT & 13.49 & -3.70 & -3.66 & -3.59 & -3.70 & -3.56 & -3.09 & -2.77 \\
\hline
\end{tabular}

The sensitivity values of 2017 influence the EBIT percentage variation $\Delta \%$ EBIT in the next financial year while the negative sign indicates that an increase in unit variable costs and/or Fixed Costs will lead to a reduction of $\Delta \%$ EBIT. With the passage of the years and the growth of the economic size and/or the improvement of the profitability there is a constant trend to the reduction of sensitivity coefficients, thus showing a greater rigidity of the company to undergo modest business policy changes.

The low values of the $\Delta \%$ EBIT sensitivity coefficients with respect to Fixed Costs do not imply that the general objective of reducing them is not worth pursuing; it only means that a percentage reduction of $1 \%$ in Fixed Costs will have a lesser impact than the same $1 \%$ increase in unit prices or that to obtain the same impact on the EBIT percentage of an increase of $1 \%$ of the unit prices will require a reduction 3.16 times in Fixed Costs, equal to the ratio existing between Production and Fixed Costs.

Secondly, it is necessary to evaluate in the planning process what the achievable objectives are in terms of the percentage variations taken into account, an activity that is not always conducted in an analytical way and very seldom oriented to dissect the percentage variations of unit prices and unit variable costs. The planner's greatest effort is aimed at evaluating the percentage variations of quantity/mix and Fixed Costs, assuming a certain immutability of unit prices and unit variable costs, at most indicating a different incidence of Total Variable Costs with respect to Production (or Revenues).

In reality, for both planning and control purposes, it is necessary to launch, even in a completely impromptu but formalized way, an analytical evaluation system of both unit prices and purchasing unit variable costs in order to have the pulse of the situation about the elements that are causing negative impacts on EBIT.

Certainly, in the larger or more structured companies this activity has been operating for decades or for many years already while in SMEs it may be absent or less structured. In my opinion this planning and control activity can modify significantly the profitability and the EBIT generation. Sometimes in SMEs it is precisely high marginality that generates the desire to increase production/sales volumes, neglecting the impact that variations in unit prices and/or unit variable costs could have on EBIT.

An analytical approach, on the other hand, is capable of highlighting the opportunities to improve profitability or to explain the reasons of a certain trend, in other words it allows the company to be managed in a more conscious way.

Table 6. Management appraisal matrix

\begin{tabular}{ccc}
\hline & $\Delta \%$ EBIT $<0$ & $\Delta \%$ EBIT $>0$ \\
\hline$\Delta \% \mathrm{BEP}<0$ & Bad \& Strange & Very Good \\
$\Delta \% \mathrm{BEP}>0$ & Bad & Good \\
\hline
\end{tabular}

Finally, it should be noted that the incentive plan for the Top Management could include some of the tools that 
have been treated; in fact it would not be entirely illogical to make a share of the MBO (of Commercial Director, Manufacturing Director and CFO) depending on the trend of $\Delta \% \mathrm{qmp}, \Delta \% \mathrm{qmcv}, \Delta \% \mathrm{pu}, \Delta \% \mathrm{cvu}$ and $\Delta \% \mathrm{CF}$ respectively and a common share on $\Delta \% \mathrm{EBIT}$ and/or $\Delta \% \mathrm{BEP}$. In particular, the Commercial Director should be measured on the joint impact that $\Delta \% \mathrm{qmp}$ and $\Delta \% \mathrm{pu}$ generate on the percentage variation of $\Delta \% \mathrm{EBIT}$ while the Manufacturing Director should be measured mainly on the impact that $\Delta \% \mathrm{cvu}$ generates on $\Delta \% \mathrm{EBIT}$.

Summarizing, the Top Management can be appraised and rewarded by analysing the percentage variation of $\triangle \% \mathrm{EBIT}$ and $\triangle \% \mathrm{BEP}$ integrated with the comparison between the value of the Potential Operating Leverage $\mathrm{LO}_{\mathrm{P}}$ and the Real Operating Leverage $\mathrm{LO}_{\mathrm{R}}$ for everything concerning the economic trend of the firm. In Table 6 we have qualitatively simplified an appraisal hypothesis that is self-explanatory.

\section{Real and Potential Operating Leverage}

Let us now examine the Real Operating Leverage $\mathrm{LO}_{\mathrm{R}}$ using the equations (29) and (8) in its definition given by the equation (1 bis):

$$
L O_{R}=\frac{\Delta \% \text { EBIT }}{\Delta \% \text { Prod }}=\frac{\operatorname{Prod}_{I^{\prime}} *[(1+\Delta \% p u) *(1+\Delta \% q m p)-1]-C V_{I} *[(1+\Delta \% c v u) *(1+\Delta \% q m c v)-1]-C F_{1} * \Delta \% C F}{E B I T_{1} *[(1+\Delta \% p u) *(1+\Delta \% q m p)-1]}
$$

From the equation (36) we derive the degree of Real or ex-post Operating Leverage; if the percentage variations of unit prices, unit variable costs and Fixed Costs are nil, we obtain that (36) can be simplified as follows:

$$
L O_{R}=\frac{\Delta \% E B I T}{\Delta \% \operatorname{Prod}}=\frac{\operatorname{Prod}_{1} * \Delta \% q m p-C V_{I^{*}} \Delta \% q m c v}{E B I T_{1} * \Delta \% q m p}=L O_{P}+\frac{C V_{I}}{E B I T_{l}} *\left(\frac{\varepsilon m p c v}{\Delta \% q m p}\right)
$$

where:

$\varepsilon m p c v=$ difference between the percentage variations of Production Mix and Variable Costs Mix

obtaining as expected the Potential or ex-ante Operating Leverage, already shown in the equation (4), provided that the factor depending on $\varepsilon m p c v$ be nil or negligible.

Consequently, as already seen above, we can relate the ex-ante Operating Leverage $\mathrm{LO}_{\mathrm{P}}$ with the ex-post Operating Leverage $\mathrm{LO}_{\mathrm{R}}$ in the equation (36) through a simple algebraic transformation:

$$
L O_{R}=\frac{\Delta \% E B I T}{\Delta \% \text { Prod }}=L O_{P} *\left(\frac{\text { Prod }_{I}}{M I_{I}}-\frac{C V_{I^{*}}[(1+\Delta \% c v u) *(1+\Delta \% q m c v)-1]+C F_{I} * \Delta \% C F}{M I_{I} *[(1+\Delta \% p u) *(1+\Delta \% q m p)-1]}\right)
$$

The latter equation represents in more compact form than the previous one what the effects are of the percentage variations of the variables that influence ex-post Operating Leverage to be managed in period 2.

In the paragraph dedicated to the Fixed Costs Variation we have hypothesized that the invariability of Fixed Costs is an excessively restrictive condition, especially in case Production variations are sensitive requiring strong increase in investments and/or personnel resulting in higher depreciations and salaries. Such a condition has been replaced by the condition that the percentage variations of Fixed Costs $\Delta \% \mathrm{CF}$ are always equal to the percentage variations in Production $\Delta \%$ Prod.

How can we modify the ex-ante Operative Leverage $\mathrm{LO}_{\mathrm{P}}$ incorporating the condition that $\Delta \% \mathrm{CF}$ is equal to $\Delta \%$ Prod? It is sufficient to replace within the equation (25) the variable $\Delta \%$ Prod with its development obtained in equation (8):

$$
\Delta \% C F=\Delta \% \operatorname{Prod}=(1+\Delta \% p u) *(1+\Delta \% q m p)-1
$$

Since in (36 bis) it is assumed that the value of $\Delta \% \mathrm{pu}$ is nil, it follows that (25) is transformed into the following condition:

$$
\Delta \% C F=\Delta \% \operatorname{Prod}=\Delta \% q m p
$$

Using this last equation, (36 bis) is transformed into the following equation (37):

$$
L O_{R}=\frac{\Delta \% E B I T}{\Delta \% \operatorname{Prod}}=\frac{\operatorname{Prod}_{1} * \Delta \% q m p-C V_{I^{*}}(\Delta \% q m p-\varepsilon m p c v)-C F_{1} * \Delta \% q m p}{E B I T_{1} * \Delta \% q m p}=100 \%+\frac{C V_{I}}{E B I T_{I}} *\left(\frac{\varepsilon m p c v}{\Delta \% q m p}\right)=L O_{a P}
$$

that can be named Adjusted Potential Operating Leverage $\mathrm{LO}_{\mathrm{aP}}$.

This result is interesting as it allows to instinctively measure how effective the Top Management is in improving the company's profitability and how much it differs from an optimal minimum situation: every time the ex-post Operating Leverage is less than $100 \%$ it translates in a condition of loss of opportunities to be investigated in depth through the tools that have been made available in the present study or other tools developed by economic analysis or company practice. On the other hand, if the EBIT percentage variation $\Delta \%$ EBIT were lower than the Production percentage variation $\Delta \%$ Prod, a warning should be automatically triggered that there is a loss of profitability, and since that is not possible in the long term, even less desirable, it should push Top Management 
to an in-depth analysis aimed to identify and remove the causes of any unsatisfactory trend. Another aspect that we wish to highlight is the possibility of using the analysis of the Degree of Operating Leverage, whether ex-ante, adjusted or unadjusted, or ex-post, at divisional, business unit (BU) or business area (BA) level or in any organizational unit where EBIT can be calculated. It is possible that if the object of calculation is subordinated to the whole company, as in the case of BA and BU, all the Variable Costs may not be included and a share of the Fixed Costs must be allocated at Headquarter level. All this does not in any way invalidate the conclusions previously presented, on the contrary splitting the analysis on subordinate objects of calculation contributes to convey the evaluation of the Operating Leverage even more analytical and precise. In a survey conducted on the empirical case under analysis, carried out at BU level, the results are so surprising and unexpected that they cannot be disclosed for the time being.

In the following Table 7 have been presented the values of the 3 definitions of Operating Leverage analysed:

- Real or ex-post Operating Leverage $\mathrm{LO}_{\mathrm{R}}$ provided by equation (1),

- Potential or ex-ante Operating Leverage $\mathrm{LO}_{\mathrm{P}}$ provided by equation (4) e

- $\quad$ Adjusted Potential Operating Leverage $\mathrm{LO}_{\mathrm{aP}}$ shown in equation (37).

Table 7 also shows the abatement percentages of the two ex-ante Operating Leverages: a negative sign indicates a reduction for both while a positive sign, considered possible only for $\mathrm{LO}_{\mathrm{aP}}$, indicates an intensification of the degree of the Operating Leverage. It must be remembered that in the business case under analysis all the management accounting data about Variable Costs are not available, so $\mathrm{empcv}$ is arbitrarily set to nil.

Table 7. Degree of operating leverages and related abatements

\begin{tabular}{|c|c|c|c|c|c|c|c|c|}
\hline Operating Leverage Abatements & 2015 & 2016 & 2017 & 2018 & 2019 & 2020 & 2021 & 2022 \\
\hline$\Delta \%$ EBIT & & $-472.289 \%$ & $2.918 \%$ & $17.643 \%$ & $28.700 \%$ & $23.160 \%$ & $28.538 \%$ & $22.099 \%$ \\
\hline$\Delta \%$ Prod & & $39.885 \%$ & $7.780 \%$ & $26.350 \%$ & $16.293 \%$ & $14.898 \%$ & $13.220 \%$ & $10.058 \%$ \\
\hline LO & $-1248.704 \%$ & $470.434 \%$ & $466.310 \%$ & $459.116 \%$ & $470.109 \%$ & $456.390 \%$ & $409.182 \%$ & $377.262 \%$ \\
\hline $\mathrm{LO}_{\mathrm{R}}$ & & $-1184.129 \%$ & $37.507 \%$ & $66.955 \%$ & $176.148 \%$ & $155.459 \%$ & $215.874 \%$ & $219.712 \%$ \\
\hline LO $_{p}$ Abatement & & $-5.171 \%$ & $-92.027 \%$ & $-85.642 \%$ & $-61.633 \%$ & $-66.931 \%$ & $-52.700 \%$ & $-46.305 \%$ \\
\hline $\mathrm{LO}_{\mathrm{aP}}$ & $100.000 \%$ & $100.000 \%$ & $100.000 \%$ & $100.000 \%$ & $100.000 \%$ & $100.000 \%$ & $100.000 \%$ & $100.000 \%$ \\
\hline LO $_{\mathrm{aP}}$ Abatement & & $-1284.129 \%$ & $-62.493 \%$ & $-33.045 \%$ & $76.148 \%$ & $55.459 \%$ & $115.874 \%$ & $119.712 \%$ \\
\hline
\end{tabular}

The abatement of the $\mathrm{LO}_{\mathrm{aP}}$ in 2016 depends on the reversal of the sign of EBIT in 2016, being the latter negative in 2015. It should be noted that all the data in the Business Plan show an intensification of the Degree of Operating Leverage. For the abatement of the $\mathrm{LO}_{\mathrm{P}}$ see the equation (5) while the abatement of the $\mathrm{LO}_{\mathrm{aP}}$ is simply the difference between $\mathrm{LO}_{\mathrm{R}}$ and $\mathrm{LO}_{\mathrm{aP}}$, which we remember is always equal or close to $100 \%$.

\section{Result Presentation}

The last point to be examined is the way in which the analysis has to be presented to Top Management in order to avoid unnecessary algebraic or technical complications that may not be appreciated or not easily understood by all members of Top Management. A possible approach is to show the variations step by step based on each single percentage variation applied in cascade, showing how each variable contributes to the final EBIT percentage variation.

In order to achieve an easily understandable result that highlights the potential of the ex-ante Operating Leverage $\mathrm{LO}_{\mathrm{P}}$, the equation (29) must be used by ordering and applying the percentage variations in the following sequence or streak:
1) $\Delta \%$ qmp and $\Delta \% \mathrm{qmcv}$
2) $\Delta \% \mathrm{pu}$
3) $\Delta \% \mathrm{cvu}$
4) $\Delta \% \mathrm{CF}$

The first step shows the impact that the percentage variation of Quantity/Mix $\Delta \%$ qmp exerts on the EBIT percentage variation $\Delta \%$ EBIT, setting all the other percentage variations to nil; using equation (29) the following result is obtained:

$$
\Delta \% E B I T=\frac{\operatorname{Prod}_{I} * \Delta \% q m p-C V_{I} * \Delta \% q m c v}{E B I T_{I}}=L O_{P} * \Delta \% q m p+\frac{C V_{I}}{E B I T_{I}} * \varepsilon m p c v
$$

The first step indicates the full unfolding of the ex-ante Operating Leverage. What result is achieved in 2017 financial year? Since the value of $\varepsilon \mathrm{mpcv}$ is unknown, it will be set to nil arbitrarily:

$$
\Delta \% E B I T \simeq L O_{P} * \Delta \% q m p=470.34 \% * 9.397 \%=44.206 \%
$$


We can also determine the absolute variation of $\triangle \mathrm{EBIT}$ due to $\triangle \% \mathrm{qmp}$ :

$$
\Delta E B I T \simeq E B I T_{1} * L O_{P} * \Delta \% q m p=2,104,183 * 44.206 \%=930,169
$$

The percentage variation of Quantity/Mix generates an EBIT percentage variation of $44.206 \%$ or $€ 930,169$, a truly remarkable potential result.

The second step introduces the impact of the percentage variation of unit prices $\Delta \% \mathrm{pu}$ and it allows to assess how the business growth (or contraction) impacted positively on the EBIT variation: if the joint variation of $\Delta \% \mathrm{qmp}$ and $\Delta \% \mathrm{pu}$ were positive, business growth would have an economic justification as well as a contraction of the variable $\Delta \% \mathrm{qmp}$ if counterbalanced by a strong increase of $\Delta \% \mathrm{pu}$ that produce an EBIT increase. For the second step we must use equation (29), considering that the variable $\Delta \% q \mathrm{mp}$ has carried out its effect in the first step already:

$$
\Delta \% E B I T=\frac{\text { Prod }_{l}}{\text { EBIT }_{l}} * \Delta \% p u *(1+\Delta \% q m p)=\frac{23,275,468}{2,104,183} *-1.478 \% *(1+9.397 \%)=-17.888 \%
$$

Consequently, the absolute variation of the EBIT will be given by:

$$
\Delta E B I T=\operatorname{Prod}_{1} * \Delta \% p u *(1+\Delta \% q m p)=23,275,468 *-1.478 \% *(1+9.397 \%)=-376,403
$$

The sales and production efforts to increase EBIT by $€ 930,169$ was offset by a loss coming from the reduction in unit prices equal to $€ 376,403$, leaving a positive net impact on EBIT of $€ 550$ thousand, corresponding to an EBIT increase of $26.3 \%$.

The introduction of the third variable, represented by the percentage variation of unit variable costs $\Delta \% \mathrm{cvu}$, it allows to evaluate if the manufacturing and supply chain activities have been able to keep the positive EBIT percentage variation or if they eroded a share of it and how large it is.

For the third step we will still use equation (29) considering that the variable $\Delta \%$ qmp has already unfold its effect in the first step. Since an approximated data of $\Delta \%$ cvu must be used, it is necessary to determine the approximation by using the following equation:

$$
-\frac{C V_{I}}{E B I T_{I}} * \Delta \% c v u *(1+\Delta \% q m c v)+\frac{C V_{I}}{E B I T_{I}} * \Delta \% c v u a *(1+\Delta \% q m p)=-\frac{C V_{I}}{E B I T_{I}} * \varepsilon m p c v
$$

The approximation is exactly equal and reverse of the approximation carried out in the equation (38).

Next equation represents the third step:

$\Delta \% E B I T=-\frac{C V_{I}}{E B I T_{1}} * \Delta \% c v u *(1+\Delta \% q m c v)=-\frac{C V_{I}}{E B I T_{l}} * \Delta \% c v u a *(1+\Delta \% q m p)-\frac{C V_{I}}{E B I T_{1}} * \varepsilon m p c$ (40 bis)

For the third step we use the equation ( $40 \mathrm{bis}$ ) considering that the variable $\Delta \% \mathrm{qmp}$ has already deployed its effect in the first step and assuming a nil value of $\varepsilon m p c v$ :

$$
\begin{array}{r}
\Delta \% E B I T=-\frac{C V_{I}}{E B I T_{1}} * \Delta \% c v u a *(1+\Delta \% q m p)-\frac{C V_{I}}{E B I T_{I}} * \varepsilon m p c v \simeq-\frac{13,376,666}{2,104,183} * 2.421 \% *(1+9.397 \%) \\
=-16.835 \%
\end{array}
$$

The impact on EBIT variation will be as follows, provided that $\mathrm{empcv}$ be nil or negligible:

$$
\Delta E B I T \simeq-C V_{l} * \Delta \% \text { cvua } *(1+\Delta \% q m p)=-13,376,666 * 2.421 \% *(1+9.397 \%)=-354,238 \text { (40 ter) }
$$

Supply Chain and/or Manufacturing eroded $16.8 \%$, corresponding to $€ 354,238$, of the excellent company performance given by the increase in the Quantity/Mix pointed out in the first step.

The last step will determine the impact of Fixed Costs variation on EBIT and will allow to reach the final evaluation of how the four variables have jointly influenced the EBIT variation. For the fourth step we will use the equation (29) for the part relating only to Fixed Costs:

$$
\Delta \% E B I T=-\frac{C F_{1}}{E B I T_{I}} * \Delta \% C F=-\frac{7,794,619}{2,104,183} * 1.772 \%=-6.565 \%
$$

The impact on the EBIT variation will be as follows:

$$
\triangle E B I T=-C F_{1} * \Delta \% C F=-7,794,619 * 1.772 \%=-138,130
$$

Fixed Costs rose by $1.772 \%$ and eroded another $6.6 \%$ of the initial EBIT percentage variation, corresponding to the entire absolute change in Fixed Costs of $€ 138,130$, and that limits the EBIT growth to just 2.9\%, corresponding to an increase of $€ 61,398$. In other words, the company effort to increase the quantity/mix $\Delta \%$ qmp by $9.397 \%$ was almost offset at EBIT level by a not excellent performance of unit prices and unit variable costs. Overall, the sales effort to increase EBIT approximately by $26.3 \%$ has been spoiled below $10 \%$ by unit variable costs.

Fortunately, the Fixed Costs variation impacts not too much negatively on EBIT percentage and absolute 
variations. Figures 2 and 3 show the EBIT percentage and absolute variations defined so far. The previous analysis shows that Fixed Costs had an increase of $1.772 \%$, lower than net Production variation equal to $7.780 \%$; in this way percentage incidence $\% c f$ fell from $33.489 \%$ to $31.622 \%$. It is necessary to remove the hypothesis of invariability of Fixed Costs to leave room to a different interpretation.

It is worthwhile presenting a third representation that highlights management actions on EBIT absolute variation by using the Adjusted Potential Operative Leverage $\mathrm{LO}_{\mathrm{aP}}$ and removing the invariability hypothesis of Fixed Costs.

What will have to be modified and what will remain unchanged with respect to the data displayed in Figure 3 ?

The EBIT variation $\Delta$ EBIT and the variations induced by $\Delta \%$ pu and $\Delta \% \mathrm{cvu}$ on EBIT will remain unchanged while the variations induced by $\Delta \% \mathrm{qmp}$ and $\Delta \% \mathrm{CF}$ must be reconsidered carefully. We have already seen that the benchmark for Fixed Costs could be the constancy of the ratio between them and the Production in the various financial years; therefore we will consider the \%cf ratio in 2016 as the basis for calculating the Maximum Fixed Costs in 2017: the difference between this theoretical value and the actual value of Fixed Costs in 2017 will be attributed to the impact that management had on Fixed Costs variation and its effect on $\Delta$ EBIT will be shown in the Figure 4.

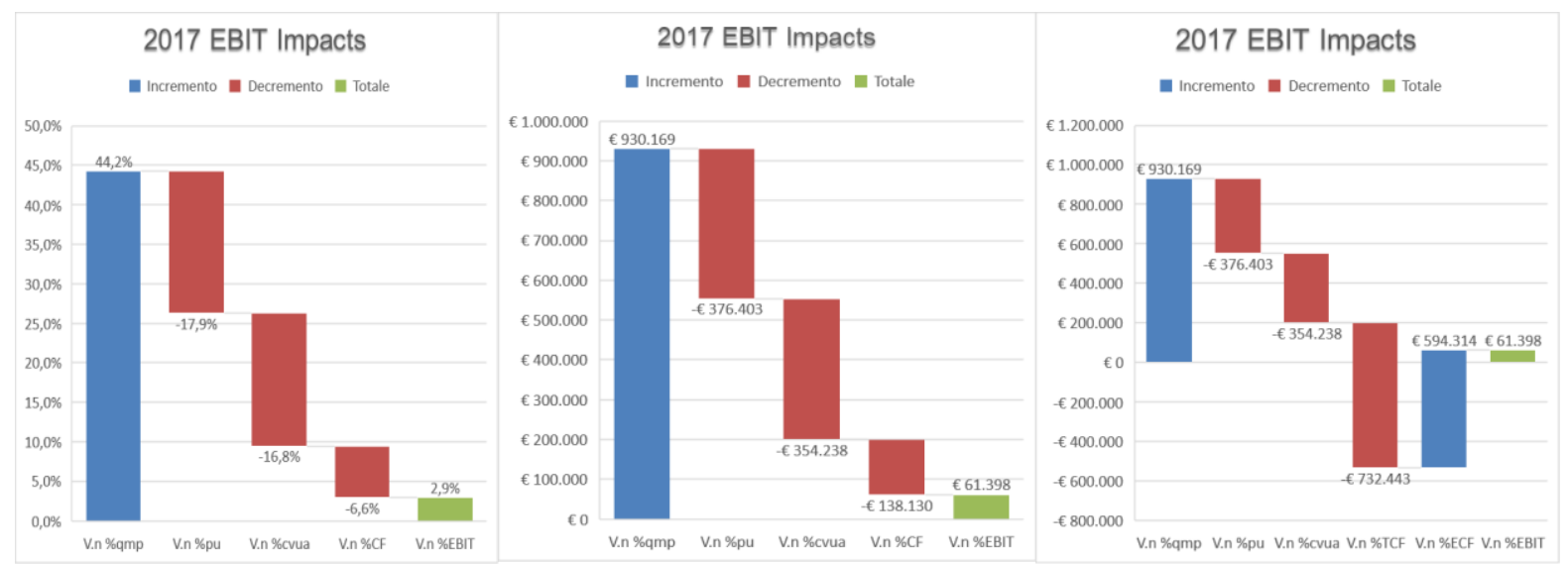

Figures 2, 3 and 4. Dynamic of 2017 EBIT percentage (left), absolute variation (middle) and absolute variation under the Adjusted Potential Operating Leverage (right)

The ratio between Fixed Costs and Production in 2016 was 33.489\%, therefore Fixed Costs should increase to affect Production with the same percentage in 2017.

Which Production value?

The Production value that would have been achieved with the same Industrial Margin $\% \mathrm{mi}_{1}$ of the previous period. To achieve this value, we use the equation (38 bis) to calculate $\triangle$ EBIT:

$$
\Delta E B I T=L O_{P} * \Delta \% q m p * E B I T_{1}=470.4 \% * 9.397 \% * 2,104,183=€ 930,169
$$

This result should be divided by the 2016 industrial margin percentage equal to $42.529 \%$ obtaining the Production variation to which the 2016 Production would be added. In this way we obtain the value that Production should have been assumed in 2017 with the same Industrial Margin $\% \mathrm{mi}_{1}$ of the previous period:

$$
\operatorname{TProd}_{2}=\operatorname{Prod}_{1}+L O_{P} * \Delta \% q m p * \frac{E B I T_{I}}{\% m i_{l}}=23,275,468+\frac{930,169}{42.529 \%}=€ 25,462,613
$$

Given the 2017 Production without any $\Delta \%$ pu variation, we now apply to this value the impact of Fixed Costs on 2016 Production; the result is the following:

$$
\operatorname{TCF}_{2}=\operatorname{TProd}_{2} * \% c f_{1}=25,462,613 * 33.489 \%=€ 8,527,062
$$

which expresses the theoretical value of the Fixed Costs at their constant impact $\% c f$ on Production over time.

Considering that the Fixed Costs value in 2017 was $€ 7,932,749$, this translates into an increase compared to 2016 of only $€ 138,130$ against a difference that could have been $€ 732,443$. The difference of $€ 594,314$ expresses the EBIT improvement in 2017 due to the impact of lower Fixed Costs.

It remains to calculate the value of EBIT attributable to the percentage variation of quantity/mix $\Delta \%$ qmp without any variations of $\Delta \% \mathrm{pu}$ and $\Delta \% \mathrm{cvu}$. 
On Production we refer to equation (42), on Fixed Costs we refer to (43) while on Variable Costs it is sufficient to apply to Theoretical Production $\operatorname{TProd}_{2}$ [see equation (42)] the same percentage that Variable Costs assumed in 2016 that was worth $57.471 \%$ :

$$
\operatorname{TCV}_{2}=\operatorname{TProd}_{2} * \% c v_{1}=25,462,613 * 57.741 \%=€ 14,633,642
$$

Table 8 summarizes the values of Production, Variable Costs, Fixed Costs and EBIT that should have been assumed in 2017 under the same conditions of 2016 and which instead have assumed with their variations:

- Columns "2016" and "2017" show the actual accounting values;

- Column " $\triangle$ As Is" shows the difference between "2017" and "2016";

- Column "To Be" shows the values that the variables should have been assumed under the same conditions of 2016 , i.e. no change of $\Delta \% \mathrm{pu}, \Delta \% \mathrm{cvu}$ and constancy of $\% c f_{1}$;

- Column " $\Delta$ To Be" shows the difference between "To Be" and "2016" columns;

- "Drifting" column shows the variations between " $\Delta$ To Be" and " $\Delta$ As Is" columns.

In summary, the EBIT variation should have been $€ 197,726$ :

- $\quad$ in presence of effective $\Delta \% \mathrm{qmp}$ variations;

- in absence of $\Delta \% \mathrm{pu}$ and $\Delta \% \mathrm{cvu}$ variations and

- at constant Fixed Costs ratio $\% c f_{1}$.

Table 8. EBIT impact determination under the adjusted potential operating leverage condition

\begin{tabular}{lccrrrr}
\hline Income St. & $\mathbf{2 0 1 6}$ & \multicolumn{1}{c}{ To Be } & \multicolumn{1}{c}{$\boldsymbol{\Delta}$ To Be } & \multicolumn{1}{l}{ Drifting } & \multicolumn{1}{c}{$\mathbf{A s}$ Is } & $\mathbf{2 0 1 7}$ \\
\hline Production & $€ 23,275,468$ & $€ 25,462,613$ & $€ 2,187,145$ & $€ 376,403 € 1,810,742 € 25,086,210$ \\
Variable Costs & $€ 13,376,666$ & $€ 14,633,642$ & $€ 1,256,976$ & $€ 354,238 € 1,611,214 € 14,987,880$ \\
Fixed Costs & $€ 7,794,619$ & $€ 8,527,062$ & $€ 732,443$ & $€ 594,314$ & $€ 138,130 \quad € 7,932,749$ \\
EBIT & $€ 2,104,183$ & $€ 2,301,909$ & $€ 197,726$ & $€ 136,328$ & $€ 61,398 \quad € 2,165,581$ \\
\hline
\end{tabular}

That being stated, the "Drifting" column indicates the EBIT variation from " $\Delta$ To Be" to " $\Delta$ As Is" and these values are summarized in Figure 4 where Fixed Costs variation has been divided into a component that represents the EBIT reduction at constant incidence $\% c f_{1}$ and the improvement actually occurred to get the final variation.

Reducing EBIT variation caused by $\Delta \% q m p$ to $€ 197,726$ from $€ 930,139$ would alter the economic significance of EBIT variation caused jointly by $\Delta \% \mathrm{pu}$ and $\Delta \% \mathrm{cvu}$.

Whatever the chosen representation will be, the arena is open to various considerations of economic and business nature.

The first considerations concern the sales department and the market demand:

- To obtain an increase in the quantities/mix $\Delta \%$ qmp equal to $9.397 \%$ it was necessary to grant a price reduction $\Delta \% \mathrm{pu}=-1.478 \%$ ? Could this cut be contained by an increase of price list or operating prices?

- Is the market demand elasticity, implicit in the ratio between $\Delta \% \mathrm{qmp}$ and $\Delta \% \mathrm{pu}$ equal to 6.358 , representative of management's expectations or would it have expected a more elastic or even more rigid demand?

These simple considerations must push Top Management to reflect on some actions to be undertaken in the commercial area aimed to increase $\Delta \% \mathrm{pu}$ without excessively penalizing $\Delta \% \mathrm{qmp}$, indeed making sure that the impact on EBIT percentage variation be positive, as in the case under analysis.

Secondly, a series of additional questions about $\Delta \%$ cvu concerning purchasing policy, manufacturing efficiency and industrialization process, due to the passage of new products from R\&D stage to Manufacturing stage, should be raised.

- What are the factors that determine the $\Delta \%$ cvu variation of $2.421 \%$ ? How much of it is due to variations in purchase costs or to a change in manufacturing efficiency associated with waste, rework, supply problems with materials and/or work-in progress?

- How could this value be modified by a reduction of purchasing materials and other related services and which of them?

- What are the main problems encountered with non-compliance (NC) and warranty repairs? How do they 
affect Variable Costs and how can they be fixed?

Finally, the Fixed Costs variation $\triangle \% \mathrm{CF}$ equal to $1.772 \%$ has produced only an impact of $-6.6 \%$ on EBIT allowing a small increase of it. In the specific case it is the least worrying variation among the negative ones examined, nevertheless it must be investigated analytically to identify areas of improvement.

In Figure 3 above it should not be overlooked that the absolute variation of Fixed Costs on EBIT is exactly equal to the absolute variation of Fixed Costs between the two financial years. This means that the incidence of Fixed Costs must decrease with respect to the Production value in order to let perform entirely the Degree of Operating Leverage and this hypothesis could prove unrealistic in some situations where the increase in Fixed Costs is due to a huge business development combined with heavy investments that increase Fixed Costs due to higher depreciation. This has already been discussed.

Table 9 provides a summary of the basic data and impacts on EBIT and Real Operating Leverage covering the period 2016-2022. It can be pointed out that sales department does not appear to be critical because the balance of EBIT impact jointly due to $\Delta \% \mathrm{qmp}$ and $\Delta \% \mathrm{pu}$ remains always positive over the years (see last column on the right).

Table 9. Data to determine the impact on EBIT from 2016 to 2022

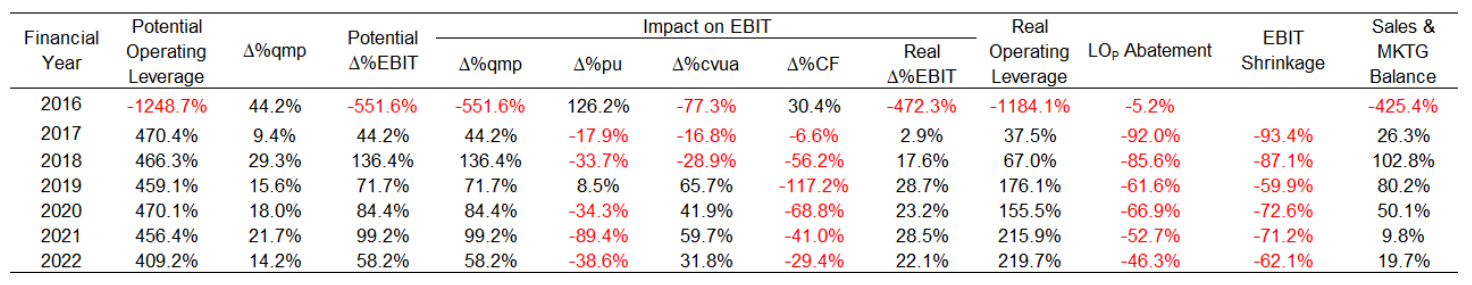

The impact of Variable Costs is negative in 2017 and 2018 to become positive in the business plan from 2019 to 2022, even with a particularly strong impact; my opinion is that natura non facit saltus, it would be necessary to monitor the trend of purchasing Variable Costs more carefully and to make properly decisions if variations impacting negatively on EBIT occur. In 2019, on the other hand, there is an impact of Fixed Costs that would result in an EBIT decrease of 117.2\%: if this variation were not offset by other positive variations, it could lead to a dangerous combination of negative effects that could lead in turn to a negative EBIT and a consequent likely loss in the income statement.

\section{Conclusions}

In this paper has been analysed the EBIT dynamic based on an in-depth investigation of some economic variations inside the framework of the Operating Leverage concept. The perspective is the internal one since it is necessary to separate Variable Costs from Fixed Costs and have a precise evaluation at least of the percentage variation of unit prices. All this makes it possible to unveil the dynamics underlying EBIT based on the results of the previous period and on the quantity, mix, price and cost percentage variations managed (or planned) in the current (or future) period.

Such a result is not immediately available by the analysis of the income statements and this makes management conducts not completely transparent to any appraisal, even if the distribution between Variable Costs and Fixed Costs is known, because a more careful evaluation of the percentage variations identified as $\Delta \% \mathrm{qmp}, \Delta \% \mathrm{qmcv}$, $\Delta \% \mathrm{pu}$ and $\Delta \% \mathrm{cvu}$ is needed.

All this makes it possible to reach an evaluation of the ex-ante business opportunity, integrated by an ex-post evaluation, and the tools made it available by the concepts of Real and Potential Operative Leverage, adjusted or unadjusted, are completely useful; besides the measure of the abatement of the Degree of Operating Leverage is a synthetic measure of how good the Top Management has been able to capture the potential of improving profitability.

Secondly, this analysis constitutes an assessment that integrates validly the information in the financial statements that measure a set of stock and flow quantities between the beginning and the end of the financial year. Such financial statements could be assimilated to two ship's points taken at a distance of time but they do not tell us much about the navigation followed between them while it could be important, in situations where the final result is negative and/or distant from the expectations, to understand in depth the reasons in order to correct the way point, even monthly or quarterly, depending on the streams, winds, waves, weather conditions, magnetic deviation and deflection, etc. 
The tools provided make it possible to better understand the resulting EBIT, the course taken at company level and to plan the future more carefully.

The study highlighted two other areas that need further investigations.

Of the first one, concerning the demand elasticity, we have already talked about while the second, concerning the impact that inventory variations on EBIT, requires further development, currently being under analysis.

We have already presented the issue of the demand elasticity in the paragraph 10. Result Presentation; we need to investigate more deeply the relationship between the variables $\Delta \% \mathrm{qmp}$ and $\Delta \% \mathrm{pu}$. To do this, it is necessary to investigate thoroughly and separate the data at least at Business Area (BA) level to have a higher product homogeneity and perhaps segmenting within the BA in even more homogeneous market/product areas.

The second one is definitely more challenging. In the data presented, inventory variations of raw materials, work in-progress and finished products were incorporated in Production and Variable Costs and equate to simple market transactions. These changes can in turn generate variations in quantity/mix and/or unit prices and/or unit variable costs. So far, we have made the implicit assumption of dumping any variation in stock solely on the quantity/mix variations. Such an assumption was necessary in order to arrive at a useful result based on the data available, namely the management accounting data and particularly the Revenues variances.

The initial choice to take into account the value of Production instead of Revenues has involved that this simplification on the inventory dynamic entails both Production and Variable Costs while the decision to opt for Revenues would have dumped inventory variation only on Variable Costs.

It is currently believed that the final results are not significantly influenced by inventory variation. In any case, it would be useful to take into account this impact and a second study is on the way in order to include explicitly inventory variations through a definition of Operating Leverage based on Revenues rather than Production.

The tools developed and made available with this paper allow to better understand the EBIT variation, the navigation followed by the firm and to plan the future course in a more precise and conscious way.

\section{References}

Alaghi, K. (2012). Operating leverage and systematic risk. African Journal of Business Management, 6(3), 1095-1099. https://doi.org/10.5897/AJBM11.2266

Brigham, E., \& Ehrhardt, M. (2011). Financial Management: Theory and Practice (13th ed., pp. 604-606). South-Western Cengage Learning, Mason.

Chiladze, I. (2017). Factor Analysis of the Enterprise's Operating Leverage. Applied Finance and Accounting, 3(1), 75-82. https://doi.org/10.11114/afa.v3i1.2050

Damodaran, A. (2001). Corporate Finance: Theory and Practice (2nd ed., pp. 202-203). John Wiley \& Sons Inc., New York.

Dugan, M. T., \& Shriver, K. A. (1992). An Empirical Comparison of Alternative Methods for the Estimation of the Degree of Operating Leverage. The Financial Review, 27(2), 309-321. https://doi.org/10.1111/j.1540-6288.1992.tb01320.x

Horngren, C. T., Datar, S. M., \& Rajan, M. (2012). Cost Accounting: A Managerial Emphasis (14th ed., pp. 76-80). Prentice Hall, Boston.

Lee, H. (2009). Using the Operating Leverage to asses operating risk of a high-tech firm: An external user's viewpoint. Journal of National Kaohsiung University of Applied Sciences, 32.

Lord, R. A. (1995). Interpreting and measuring operating leverage. Issues in Accounting Education, 10(2), 317-326.

O'Brien, T. J., \& Vanderheiden, P. A. (1987). Empirical Measurement of Operating Leverage for Growing Firms. Financial Management, 16(2), 45-53. https://doi.org/10.2307/3666003

Schönenberger, F. (2014). Operating Leverage - Is cost structure rigidity a characteristic of Risk? The impact of cost structure rigidity on returns under consideration of BM ratio and size. $\mathrm{PhD}$ Dissertation of the University of St. Gallen, School of Management.

Sinha, S. (2012). Operating Leverage Analysis - A Conceptual Framework. Journal of Business Management, 3(2), 8-27. https://doi.org/10.9790/487X-0320827 


\section{Appendix A}

\section{Management accounting details}

The paragraph relating to multi-product companies has introduced a transform of some percentage variations of prices, quantities and mixes. We exemplify the general case with an ordinary but effective numerical example. Let us assume that a manufacturer of pens sells two products, A and B, in 2017 and 2018 at prices and quantities indicated in the Table A.1 showing a Revenues variation equal to $14.466 \%$ with quantities increased by $13.333 \%$. Product A suffered a price drop of $1.667 \%$ while product B had a price increase of $2.857 \%$. Both products increased the quantities sold but the mix was in favour of B product as its increase was $14.286 \%$ while the increase of A stopped at $10 \%$. The weighted average price increased by $0.999 \%$.

Management accounting can show:

- a Quantity Variance of $€ 486.67$, equal to an increase of $13.333 \%$ (compared to 2017 Revenues);

- a negative Mix Variance of $€ 16.67$, equal to a reduction of $0.457 \%$;

- a positive Price Variance of $€ 58.00$, equal to an increase of $1.589 \%$

for a total Revenues variance of $€ 528.00$, equal to an increase of $14.466 \%$.

The following considerations apply to Variable Costs:

- a Quantity variance of $€ 273.33$ equal to an increase of $13.333 \%$;

- a negative Mix variance of $€ 8.33$, equal to a reduction of $0.407 \%$;

- a positive Cost variance of $€ 113.00$, equal to an increase of $5.512 \%$

for a total Variable Costs variance of $€ 378.00$, equal to an increase of $18.439 \%$.

The following considerations apply to Industrial Margins:

- a Quantity variance of $€ 213.33$ equal to an increase of $13.333 \%$;

- a negative Mix variance of $€ 8.33$ equal to a reduction of $0.521 \%$;

- a negative Margin variance of $€ 55.00$ equal to a reduction of $3.437 \%$

for a total Industrial Margins variance of $€ 150.00$ equal to an increase of $9.375 \%$.

The numerical example shows that the extremely analytical variances calculated by management accounting differ from the statistical variations because all the quantity percentage variations are the same but all the other percentage variations are linked in a complex relationship in order to obtain the same Revenues, Variable Costs and Industrial Margins variations. It should be noted that the quantity percentage variance $\Delta \% \mathrm{q}$ is always the same, regardless of the economic quantity to which it refers to, and is equal to the same variation statistically calculated. Mix variations change, albeit slightly, depending on the economic quantity investigated.

Table A.1. Numerical example to examine different percentage variations

\begin{tabular}{|c|c|c|c|c|c|c|c|c|c|}
\hline Year & Product & Quantity & Mix & Unit Price & $\begin{array}{l}\text { Unit Variable } \\
\text { Cost }\end{array}$ & $\begin{array}{c}\text { Unit Industrial } \\
\text { Margin }\end{array}$ & Revenues & $\begin{array}{l}\text { Variable } \\
\text { Costs }\end{array}$ & $\begin{array}{c}\text { Industrial } \\
\text { Margin }\end{array}$ \\
\hline \multirow{3}{*}{2017} & A & 100.00 & $22.22 \%$ & $€ 12.00$ & $€ 6.50$ & $€ 5.50$ & $€ 1,200.00$ & $€ 650.00$ & $€ 550.00$ \\
\hline & B & 350.00 & $77.78 \%$ & $€ 7.00$ & $€ 4.00$ & $€ 3.00$ & $€ 2,450.00$ & $€ 1,400.00$ & $€ 1,050.00$ \\
\hline & Total & 450.00 & $100.00 \%$ & $£ 8.11$ & $£ 4.56$ & $£ 3.56$ & $£ 3,650.00$ & $£ 2,050.00$ & $€ 1,600.00$ \\
\hline \multirow{3}{*}{2018} & A & 110.00 & $21.57 \%$ & $€ 11.80$ & $€ 6.80$ & $€ 5.00$ & $€ 1,298.00$ & $€ 748.00$ & $€ 550.00$ \\
\hline & B & 400.00 & $78.43 \%$ & $€ 7.20$ & $€ 4.20$ & $€ 3.00$ & $€ 2,880.00$ & $€ 1,680.00$ & $€ 1,200.00$ \\
\hline & Total & 510.00 & $100.00 \%$ & € 8.19 & $€ 4.76$ & € 3.43 & € 4,178.00 & E 2,428.00 & € $1,750.00$ \\
\hline \multirow{3}{*}{$\begin{array}{l}\text { \% Variations } \\
2018 \text { vs. } 2017\end{array}$} & A & $10.000 \%$ & & $-1.667 \%$ & $4.615 \%$ & $-9.091 \%$ & $8.167 \%$ & $15.077 \%$ & $0.000 \%$ \\
\hline & B & $14.286 \%$ & & $2.857 \%$ & $5.000 \%$ & $0.000 \%$ & $17.551 \%$ & $20.000 \%$ & $14.286 \%$ \\
\hline & Total & $13.333 \%$ & & $0.999 \%$ & $4.505 \%$ & $-3.493 \%$ & $14.466 \%$ & $18.439 \%$ & $9.375 \%$ \\
\hline Year & Product & $\Delta$ Q.ty & $\Delta \mathrm{Mix}$ & $\Delta$ Price & $\begin{array}{c}\Delta \text { Variable } \\
\text { Costs }\end{array}$ & $\begin{array}{c}\Delta \text { Industrial } \\
\text { Margin }\end{array}$ & $\Delta$ Revenues & $\begin{array}{c}\Delta \text { Variable } \\
\text { Costs }\end{array}$ & $\begin{array}{c}\Delta \text { Industria } \\
\text { Margin }\end{array}$ \\
\hline \multirow{12}{*}{$\begin{array}{l}\text { Variances } \\
2018 \text { vs. } 2017\end{array}$} & A & $€ 160.00$ & $-€ 40.00$ & $-€ 22.00$ & & & $€ 98.00$ & & \\
\hline & B & $€ 326.67$ & $€ 23.33$ & $€ 80.00$ & & & $€ 430.00$ & & \\
\hline & Total & $€ 486.67$ & $-€ 16.67$ & $£ 58.00$ & & & $€ 528.00$ & & \\
\hline & \%Variances & $13.333 \%$ & $-0.457 \%$ & $1.589 \%$ & & & $14.466 \%$ & & \\
\hline & A & $€ 86.67$ & $-€ 21.67$ & & $€ 33.00$ & & & $€ 98.00$ & \\
\hline & B & $€ 186.67$ & $€ 13.33$ & & $€ 80.00$ & & & $€ 280.00$ & \\
\hline & Total & £ 273.33 & $-€ 8.33$ & & $€ 113.00$ & & & $€ 378.00$ & \\
\hline & \% Variances & $13.333 \%$ & $-0.407 \%$ & & $5.512 \%$ & & & $18.439 \%$ & \\
\hline & A & $€ 73.33$ & $-€ 18.33$ & & & $-€ 55.00$ & & & $€ 0.00$ \\
\hline & B & $€ 140.00$ & $€ 10.00$ & & & $€ 0.00$ & & & $€ 150.00$ \\
\hline & Total & € 213.33 & $-€ 8.33$ & & & $-€ 55.00$ & & & $€ 150.00$ \\
\hline & \% Variances & $13.333 \%$ & $-0.521 \%$ & & & $-3.437 \%$ & & & $9.375 \%$ \\
\hline
\end{tabular}


Starting from management accounting data and adding together the variance of quantity and mix, the term $\Delta \% \mathrm{qma}$ is obtained that varies according to the economic quantity to which is referred to.

For Revenues, the sum of the quantity and mix variances $\Delta \% \mathrm{qmp}$ is $12.877 \%$, which determines a variation of $1.408 \%$ in unit price $\Delta \% \mathrm{pu}$, lower than the price variance $\Delta \%$ p equal to $1.589 \%$ but higher than the average weighted price variation $\Delta \% \mathrm{pm}$ equal to $0.999 \%$.

Mutatis mutandis, the same considerations apply to Variable Costs and Industrial Margins. In all the three perspectives, the total variations in Revenues, Variable Costs and Industrial Margins must be the same, both starting from management accounting data, statistical data or transform of management accounting data. As a matter of fact, starting from the three different representations, the total percentage variation is always equal to 14.466\% for Revenues, $18.439 \%$ for Variable Costs and $9.375 \%$ for Industrial Margins.

Table A.2. Comparison of different percentage variations

\begin{tabular}{|c|c|c|c|c|c|c|c|c|}
\hline & $\Delta \% q$ & $\Delta \% \mathrm{~m}$ & $\Delta \% p$ & $\Delta \% c \mathrm{c}$ & $\Delta \% \mathrm{mi}$ & $\begin{array}{c}\Delta \% \\
\text { Revenues }\end{array}$ & $\begin{array}{c}\Delta \% \text { Variable } \\
\text { Costs }\end{array}$ & $\begin{array}{c}\Delta \% \text { Industrial } \\
\text { Margin }\end{array}$ \\
\hline \multirow{3}{*}{$\begin{array}{l}\text { Management } \\
\text { Accounting }\end{array}$} & $13.333 \%$ & $-0.457 \%$ & $1.589 \%$ & & & $14.466 \%$ & & \\
\hline & $13.333 \%$ & $-0.407 \%$ & & $5.512 \%$ & & & $18.439 \%$ & \\
\hline & $13.333 \%$ & $-0.521 \%$ & & & $-3.437 \%$ & & & $9.375 \%$ \\
\hline \multirow{2}{*}{ Statistic } & $\Delta \% q$ & & $\Delta \% \mathrm{pm}$ & $\Delta \% \mathrm{cvm}$ & $\Delta \% \operatorname{mim}$ & & & \\
\hline & $13.333 \%$ & & $0.999 \%$ & $4.505 \%$ & $-3.493 \%$ & $14.466 \%$ & $18.439 \%$ & $9.375 \%$ \\
\hline \multirow{4}{*}{ Trasform } & \multicolumn{2}{|c|}{$\Delta \% q m$} & $\Delta \%$ pu & $\Delta \%$ cvu & $\Delta \%$ miu & & & \\
\hline & \multicolumn{2}{|c|}{$12.877 \%$} & $1.408 \%$ & & & $14.466 \%$ & & \\
\hline & \multicolumn{2}{|c|}{$12.927 \%$} & & $4.881 \%$ & & & $18.439 \%$ & \\
\hline & \multicolumn{2}{|c|}{$12.813 \%$} & & & $-3.047 \%$ & & & $9.375 \%$ \\
\hline
\end{tabular}

The reason why the transform of management accounting data is used is twofold: on one hand, it allows a correct representation of the unit variation of the related variable, for example the unit price, since the price variance, or variable cost or Industrial Margin variance, is influenced by a component depending on the increase in quantity/mix and on the other hand, in the absence of cost management accounting and in the presence of sufficiently tight economic conditions, it allows to reach conclusions important that otherwise would not be obtainable without detailed information.

It is necessary to determine the relationships existing between the different percentage variations examined and to do this we will make use of a generic economic variable A that could represent Revenues, Production, Variable Costs or Industrial Margins.

We have already seen in the equation (8) the relationship between the percentage variation of Production expressed through the variables of management accounting, statistics and the transform proposed.

We generalize this equation for an economic quantity A characterized by unit value vu and quantity q; equation (8) changes in (45):

$\Delta \% A=\Delta \% q+\Delta \% m a+\Delta \% v=(1+\Delta \% v m) *(1+\Delta \% q)-1=(1+\Delta \% v u) *(1+\Delta \% q m a)-1$

from which we go back to the original equation in its statistical and transform form:

$$
A_{1}=\sum_{i=1}^{n}{ }_{i} v u_{1} *{ }_{i} q_{1}=v m_{1} * \sum_{i=1}^{n}{ }_{i} q_{1}=v m_{1} * q_{1}=v u_{1} * q m a_{1}
$$

What is the relationship between all the variables in (45)?

By definition we know that the following relation is valid in the transform:

$$
\Delta \% q m a=\Delta \% q+\Delta \% m a
$$

Using (9) we can determine $\Delta \% \mathrm{vu}$ depending on the management accounting and/or statistics variables presented in Table A.2:

$$
\begin{array}{r}
\Delta \% v u=\frac{\Delta \% v}{(1+\Delta \% q m a)} \\
\Delta \% v u=\frac{\Delta \% v m *(1+\Delta \% q)-\Delta \% m a}{(1+\Delta \% q m a)}
\end{array}
$$

The notation $\Delta \% \mathrm{vu}$ is applicable to the percentage variation of unit prices, unit variable costs and unit industrial margins starting from the related percentage variance $\Delta \% \mathrm{v}$ or the related weighted average value $\Delta \%$ vm.

We apply equations (47) and (48) to analyse unit prices:

$$
\Delta \% p u=\frac{\Delta \% p}{(1+\Delta \% q m p)}=\frac{1.589 \%}{(1+13.333 \%-0.457 \%)}=1.408 \%
$$




$$
\Delta \% p u=\frac{\Delta \% p m *(1+\Delta \% q)-\Delta \% m p}{(1+\Delta \% q m p)}=\frac{0.999 \% *(1+13.333 \%)+0.457 \%}{(1+13.333 \%-0.457 \%)}=1.408 \%
$$

The notation represented in equation (46) below allows to transform a relation with statistical meaning into a relation with economic meaning, more apt to represent the percentage variations that have been previously examined:

$$
A_{1}=\sum_{i=1}^{n}{ }_{i} v u_{1} *{ }_{i} q_{1}=v m_{1} * q_{1}=v u_{1} * q m a_{1}
$$

Let us go into the details of the management accounting variances to analyse how they are calculated with reference to the generic economic quantity A.

In the following four equations we will examine the variances of Quantity, Mix, Value and Total of A:

$$
\begin{gathered}
\Delta Q=\sum_{i=1}^{n}\left(q_{2}-q_{1}\right){ }_{i} m a_{1} *{ }_{i} v u_{1}=\left(q_{2}-q_{1}\right) * v m_{1} \\
\Delta M=\sum_{i=1}^{n} q_{2} *\left({ }_{i} m a_{2}-{ }_{i} m a_{1}\right) *{ }_{i} v u_{1}=q_{2} \sum_{i=1}^{n}{ }_{i} m a_{2} *{ }_{i} v u_{1}-q_{2} * v m_{1}=q_{2} *\left(v_{1} m_{2}-v m_{1}\right) \\
\Delta V=\sum_{i=1}^{n} q_{2} *{ }_{i} m a_{2} *\left({ }_{i} v u_{2}-{ }_{i} v u_{1}\right)=q_{2} * v m_{2}-q_{2} \sum_{i=1}^{n} m a_{2} *{ }_{i} v u_{1}=q_{2} *\left(v m_{2}-v m_{2}\right) \\
\Delta A=\Delta Q+\Delta M+\Delta V=q_{2} * v m_{2}-q_{1} * v m_{1}
\end{gathered}
$$

From the previous equations of management accounting, we note that both the mix variance and the price variance of $\mathrm{A}$ are influenced by a term that represents the average value of the various ${ }_{i} \mathrm{vu}_{1}$ weighted with the mix of the following period. We have simplified this notation in the following way:

$$
\sum_{i=1}^{n}{ }_{i} m a_{2} *{ }_{i} v u_{1}=v_{1} m_{2}
$$

to distinguish it from the weight of ${ }_{\mathrm{i}} \mathrm{Vu}_{1}$ and ${ }_{\mathrm{i}} \mathrm{vu}_{2}$ with the mix of the corresponding period 1 and 2 respectively. Let us now move from the absolute variations to the percentage variations obtainable by comparing them to the value of the quantity $\mathrm{A}$ in the period 1; the following equations can be easily achieved:

$$
\begin{aligned}
& \frac{\Delta Q}{A_{1}}=\frac{\left(q_{2}-q_{1}\right) * v m_{1}}{q_{1} * v m_{1}}=\frac{\left(q_{2}-q_{1}\right)}{q_{1}}=\Delta \% q \\
& \frac{\Delta M}{A_{l}}=\frac{q_{2} *\left(v_{1} m_{2}-v m_{l}\right)}{q_{1} * v m_{l}}=(1+\Delta \% q) *\left(\frac{v_{1} m_{2}}{v m_{l}}-1\right)=(1+\Delta \% q) *\left(\rho v_{1}-1\right)=\Delta \% m a \\
& \frac{\Delta V}{A_{1}}=\frac{q_{2} *\left(v m_{2}-v_{l} m_{2}\right)}{q_{1} * v m_{1}}=(1+\Delta \% q) *\left(1+\Delta \% v m-\frac{v_{l} m_{2}}{v m_{l}}\right)=(1+\Delta \% q) *\left(1+\Delta \% v m-\rho v_{1}\right)=\Delta \% v \\
& \Delta \% A=\frac{\Delta A}{A_{l}}=\frac{\Delta Q+\Delta M+\Delta V}{A_{l}}=\Delta \% q+\Delta \% m a+\Delta \% v
\end{aligned}
$$

\begin{tabular}{|c|c|c|c|c|c|c|}
\hline Products & $\mathrm{pm}_{1}$ & $p_{1} m_{2}$ & $\operatorname{cvm}_{1}$ & $\mathrm{cv}_{1} \mathrm{~m}_{2}$ & $\operatorname{mim}_{1}$ & $\mathrm{mi}_{1} \mathrm{~m}_{2}$ \\
\hline A & $€ 2.67$ & $€ 2.59$ & $€ 1.44$ & $€ 1.40$ & $€ 1.22$ & $€ 1.19$ \\
\hline B & $€ 5.44$ & $€ 5.49$ & $€ 3.11$ & $€ 3.14$ & $€ 2.33$ & $€ 2.35$ \\
\hline \multirow[t]{5}{*}{ Total } & $€ 8.11$ & $€ 8.08$ & $€ 4.56$ & $€ 4.54$ & $€ 3.56$ & $€ 3.54$ \\
\hline & \multicolumn{2}{|c|}{$\rho p_{1}$} & \multicolumn{2}{|c|}{$\rho c v_{1}$} & \multicolumn{2}{|c|}{$\rho \mathrm{mi}_{1}$} \\
\hline & \multicolumn{2}{|c|}{$99.597 \%$} & \multicolumn{2}{|c|}{$99.641 \%$} & \multicolumn{2}{|c|}{$99.540 \%$} \\
\hline & \multicolumn{2}{|c|}{$\Delta$} & \multicolumn{2}{|c|}{$-0.044 \%$} & \multicolumn{2}{|c|}{$0.057 \%$} \\
\hline & \multicolumn{2}{|c|}{$\Pi$} & \multicolumn{2}{|c|}{$99.240 \%$} & \multicolumn{2}{|c|}{$99.139 \%$} \\
\hline
\end{tabular}

We have simplified the relationship between $\mathrm{v}_{1} \mathrm{~m}_{2}$ and $\mathrm{vm}_{1}$ calling it $\rho \mathrm{v}_{1}$. As it can be seen from equation (57), when this ratio is different from 1, it generates the Mix of A and it is the determiner of the difference in value of the Price, Variable Costs and Industrial Margins Mix variances that in Table A.2 they assume respectively the values of $0.457 \%, 0.407 \%$ and $0.521 \%$. It follows that $\rho v_{1}$ takes different values for unit price, unit variable cost and unit industrial margin and in fact this ratio is worth $99.597 \%, 99.641 \%$ and $99.540 \%$ respectively (see Table A.3).

Table A.3. Assessment of the three different $\rho v_{1}$

In this simple case it is quite easy to determine the management accounting variances because the data presented in Table A.1 have been imagined. In the real world, reaching these values is not so easy for several reasons.

The first reason concerns the collection of Revenues data, which is relatively simple, easily achievable in structured and organized companies, but not always implemented for reasons beyond the present dissertation.

The second reason concerns the collection and allocation of Variable Costs to the products. Such a task requires a relatively complex information system and the allocation of a share close to the totality of all the productive factors in the bill of materials together with the allocation of scraps and reworkings through the quality system. 
This practice is not entirely common in SMEs. The consequence is that many companies have not a precise knowledge of the manufacturing costs of each single product; therefore, cost accounting is not immediately feasible. Even the analysis of Industrial Margins becomes difficult if not impossible. Since the determination of price variances is much easier than cost variances, is it possible to use the former to make inductions on the latter? Within certain limits the answer is yes and that depends on two factors:

1) from the variable $\rho v_{1}$ and from the value it assumes for the unit prices $\rho p_{1}$ and for the unit variable costs $\rho \mathrm{cv}_{1}$;

2) from the extent of the quantity variance $\Delta \% \mathrm{q}$.

Let's imagine that we have detailed information on price variances and have no clue about variable cost variances. We see that the Quantity percentage variance $\Delta \% \mathrm{q}$ is common to every variance. Can we assume that the percentage variance of the Variable Costs Mix is sufficiently similar to the Revenues Mix one? Within certain limits, yes, even though we fall into an error but the applicability depends on its entity: what error and how to determine it?

The first error we incur is relative to the mix and consequently to the sum of percentage variation of quantity and mix. The second error affects the percentage variation in the unit variable cost $\Delta \%$ cvu. Let us see both in detail; let us start with the Mix empcv error between Revenues and Variable Costs:

$$
\text { empcv }=\Delta \% \mathrm{mp}-\Delta \% \mathrm{mcv}=(1+\Delta \% \mathrm{q}) *\left(\rho \mathrm{p}_{1}-\rho \mathrm{cv}_{1}\right)=(1+13.333 \%) *(99.597 \%-99.641 \%)=0.050 \%
$$

The smaller the difference between the $\rho v_{1}$ of unit price and unit variable cost and the smaller will be the error. The percentage variation of quantity $\Delta \% \mathrm{q}$ acts as a multiplier. In the example the mix error $\mathrm{empcv}$ is $0.050 \%$, small but not zero, equal to the difference between the Production Mix $-0.457 \%$ and the Variable Costs Mix $-0.407 \%$.

The second error that occurs is the value of $\Delta \% \mathrm{cvu}$, definitely more important for economic purposes. Such an error depends on the replacement of the quantity/mix percentage variation $\Delta \% \mathrm{qmcv}$ relative to the Variable Costs with percentage variation $\Delta \% \mathrm{qmp}$ relative to Production, the most easily discoverable value:

$$
\varepsilon \mathrm{cvu}=\frac{\Delta \% \mathrm{cv}}{(1+\Delta \% \mathrm{qmcv})}-\frac{\Delta \% \mathrm{cv}}{(1+\Delta \% \mathrm{qmp})}=(1+\Delta \% \mathrm{cvm}) * \frac{\rho \mathrm{p}_{1}-\rho \mathrm{cv}_{1}}{\rho \mathrm{p}_{1} * \mathrm{cvv}_{1}}=(1+4.505 \%) * \frac{(99.597 \%-99.641 \%)}{(99.597 \% * 99.641 \%)}=-0.047 \%
$$

Equation (60) was obtained after long algebraic passages and generates an error equal to $-0.047 \%$, exactly the difference between the right value of $\Delta \% \mathrm{cvu}$ and the approximated one $\Delta \%$ cvua obtained by using the Revenues percentage variation of quantity/mix instead of the Variable Costs one. The error essentially depends on the extent of the mix of Revenues and Variable Costs, calculated using the difference between $\rho p_{1}$ and $\rho \mathrm{cv}_{1}$ compared to their product while the weighted average variable cost percentage variation acts as a multiplier. Table A.4 shows all the percentage variations discussed in the present Appendix A.

\begin{tabular}{|c|c|c|c|c|c|c|c|c|}
\hline & $\Delta \% q$ & $\Delta \% m$ & $\Delta \% p$ & $\Delta \% \mathrm{cv}$ & $\Delta \% \mathrm{mi}$ & $\begin{array}{c}\Delta \% \\
\text { Revenues }\end{array}$ & $\begin{array}{c}\Delta \% \text { Variable } \\
\text { Costs }\end{array}$ & $\begin{array}{c}\Delta \% \text { Industria } \\
\text { Margin }\end{array}$ \\
\hline \multirow{3}{*}{$\begin{array}{l}\text { Management } \\
\text { Accounting }\end{array}$} & $13.333 \%$ & $-0.457 \%$ & $1.589 \%$ & & & $14.466 \%$ & & \\
\hline & $13.333 \%$ & $-0.407 \%$ & & $5.512 \%$ & & & $18.439 \%$ & \\
\hline & $13.333 \%$ & $-0.521 \%$ & & & $-3.437 \%$ & & & $9.375 \%$ \\
\hline \multirow{2}{*}{ Statistic } & $\Delta \% q$ & & $\Delta \% \mathrm{pm}$ & $\Delta \%$ cvm & $\Delta \% \operatorname{mim}$ & & & \\
\hline & $13.333 \%$ & & $0.999 \%$ & $4.505 \%$ & $-3.493 \%$ & $14.466 \%$ & $18.439 \%$ & $9.375 \%$ \\
\hline \multirow{4}{*}{ Trasform } & \multicolumn{2}{|c|}{$\Delta \% q m$} & $\Delta \%$ pu & $\Delta \%$ cvu & $\Delta \%$ miu & & & \\
\hline & \multicolumn{2}{|c|}{$12.877 \%$} & $1.408 \%$ & & & $14.466 \%$ & & \\
\hline & \multicolumn{2}{|c|}{$12.927 \%$} & & $4.881 \%$ & & & $18.439 \%$ & \\
\hline & \multicolumn{2}{|c|}{$12.813 \%$} & & & $-3.047 \%$ & & & $9.375 \%$ \\
\hline & \multirow{2}{*}{\multicolumn{2}{|c|}{$\begin{array}{l}12.877 \% \\
12.877 \%\end{array}$}} & $1.408 \%$ & & & $14.466 \%$ & & \\
\hline Approximate & & & & $4.928 \%$ & & & $18.439 \%$ & \\
\hline \multirow[t]{2}{*}{ Trasform } & \multicolumn{2}{|c|}{$12.877 \%$} & & & $-3.102 \%$ & & & $9.375 \%$ \\
\hline & \multicolumn{2}{|c|}{ Error } & $0.000 \%$ & $-0.047 \%$ & $0.055 \%$ & & & \\
\hline
\end{tabular}

Table A.4. Comparison of the different percentage variations

For completeness, we also report the equations that allow the error computations for the Industrial Margin starting from the Revenues variances:

$$
\begin{gathered}
\varepsilon \text { mpmi }=\Delta \% \mathrm{mp}-\Delta \% \mathrm{mmi}=(1+\Delta \% \mathrm{q}) *\left(\rho \mathrm{p}_{1}-\rho \mathrm{mi}_{1}\right)=(1+13.333 \%) *(99.597 \%-99.540 \%)=0.064 \% \\
\varepsilon \mathrm{miu}=\frac{\Delta \% \mathrm{mi}}{(1+\Delta \% \mathrm{qmmi})}-\frac{\Delta \% \mathrm{mi}}{(1+\Delta \% \mathrm{qmp})}=(1+\Delta \% \mathrm{mim}) * \frac{\rho \mathrm{p}_{1}-\rho \mathrm{mi}_{1}}{\rho \mathrm{p}_{1} \mathrm{pmi}_{1}}==(1-3.493 \%) * \frac{(99.597 \%-99.540 \%)}{(99.597 \% * 99.540 \%)}=-0.055 \%
\end{gathered}
$$




\section{Appendix B}

\section{Mix Errors}

In the present Appendix we shall deal with the variation of the $\varepsilon m p c v$ and $\varepsilon c v u$ errors when Revenues and Variable Costs Mixes vary by using the numerical example already presented in Table A.1. To obtain Mix variations and calculate the error, we will change continuously the quantities of Product B in 2017 and 2018 from 0 to 700 units. In the following Figures the B quantities in 2018 will be represented on the abscissa and on the ordinate the B quantities in 2017 while the areas represent the values of the measures under investigation. Product A will keep the quantities sold in 2017 and 2018 constant, respectively 100 and 110 units. Any other parameter will remain unchanged. For this purpose, we shall use the equations related to the errors $\varepsilon m p c v$ and $\varepsilon c v u$ already presented in equations (59) and (60).

In Figure B.1 we find $\varepsilon m p c v$ error which represents the difference between the Revenues mix and the Variable Costs mix; the yellow line indicates both the quantity pairs that give rise to a null $\mathrm{empcv}$ and the area of separation of the negative values below from the positive ones above. In Figure B.1 we can see that if the quantities sold in 2017 exceeds the level of 250 units, empcv would always be within a range of $+/-2.5 \%$, a relatively low value.

In Figure B.2 we present the trend of $\Delta \% \mathrm{q}$ with the change in the B quantities sold at constant trend of $\mathrm{A}$. The yellow line indicates both the pairs of quantities that give rise to a null $\Delta \% \mathrm{q}$ and the area of separation of negative values above from the positive ones below. Over the 300 units sold in 2017 the value of $\Delta \% \mathrm{q}$ is always included in a range between $+/-100 \%$, reaching values that could cause important $\varepsilon m p c v$ values.

In Figure B.3 we present how ecvu varies as the B quantity sold change while the trend of A quantity is unchanged. The yellow line indicates both the quantity pairs that give rise to a null $\varepsilon c v u$ and the area of separation of the negative values below from the positive ones above. Over the 250 units sold both in 2017 and 2018 , the $\varepsilon \mathrm{cvu}$ value is included in a range between $+/-1.00 \%$.
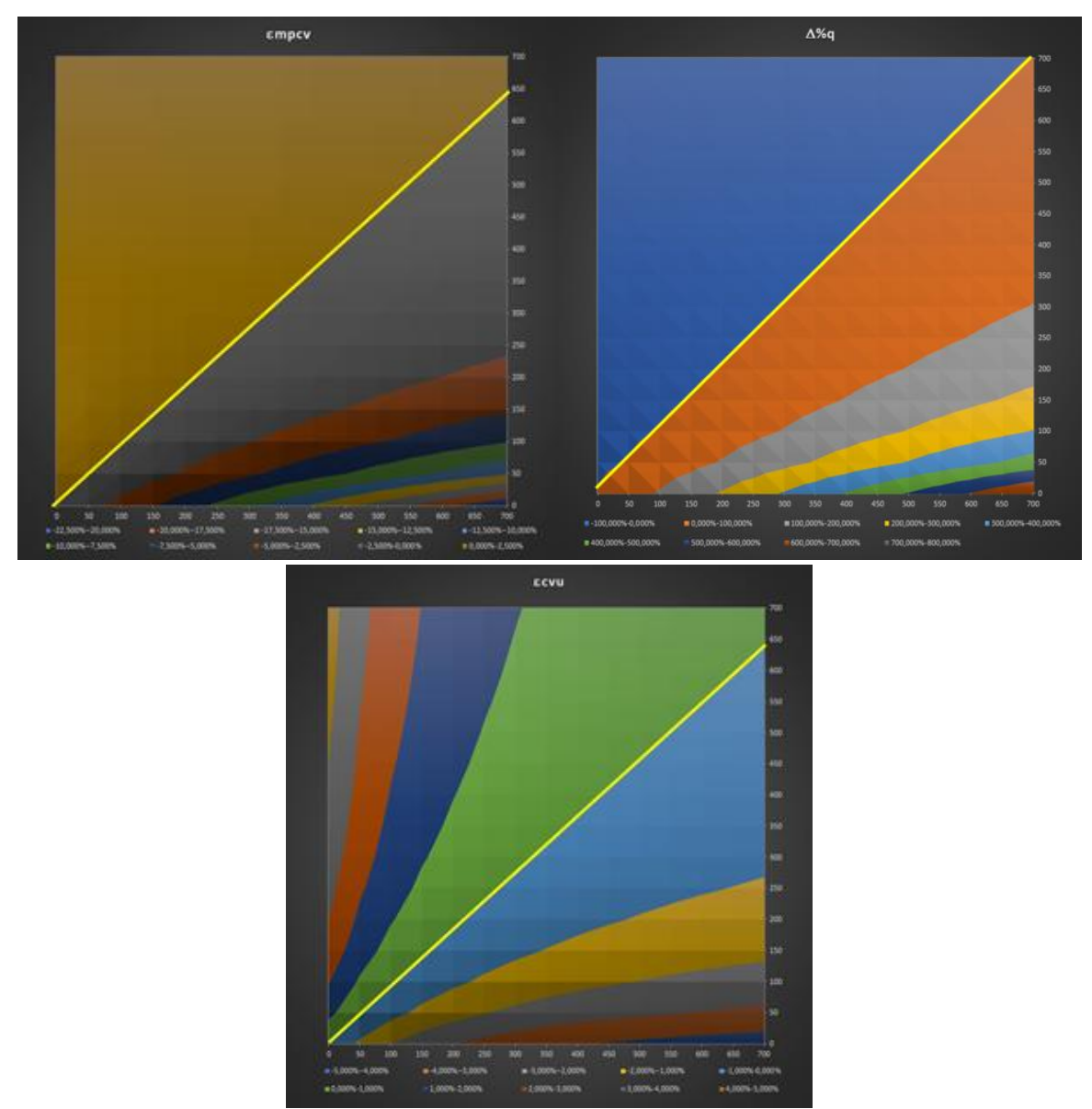

Figures B.1, B.2 and B.3. Excursion of $\varepsilon m p c v$ (above left), $\Delta \%$ q (above right) and $\varepsilon c v u$ (below middle) as B varies at constant trend of $\mathrm{A}$ 
From the data presented in Table A.4 it is known that the ecvu error is equal to $-0.047 \%$, indeed small and therefore acceptable. Unfortunately, in the case of the company under analysis the error is unknown and in the absence of better information on Variable Costs and related variances, an approximate value of $\Delta \% \mathrm{cvu}$ was assumed, namely $\Delta \%$ cvua.

The applicability of an approximate model could be anyway valid and still can have areas of not modest acceptability but the data that the management accounting could make available are priceless and allow to reach the precision necessary to ensure that the corporate decision-making process is not flawed by coarse errors.

\section{Copyrights}

Copyright for this article is retained by the author(s), with first publication rights granted to the journal.

This is an open-access article distributed under the terms and conditions of the Creative Commons Attribution license (http://creativecommons.org/licenses/by/4.0/). 